Dalia Liuzzi, Ekain Fernandez*, Susana Perez, Enrique Ipiñazar, Amaya Arteche, José Luís G. Fierro, Jose Luis Viviente, David Alfredo Pacheco Tanaka and Sergio Rojas*

\title{
Advances in membranes and membrane reactors for the Fischer-Tropsch synthesis process for biofuel production
}

https://doi.org/10.1515/revce-2019-0067

Received October 2, 2019; accepted February 23, 2020

Abstract: The biomass-to-liquid (BtL) process is a promising technology to obtain clean, liquid, second-generation biofuels and chemicals. The BtL process, which comprises several steps, is based upon the gasification of biomass and the catalytic transformation of the syngas that is obtained via the Fischer-Tropsch synthesis (FTS) reaction, producing a hydrocarbon pool known as syncrude. The FTS process is a well-established technology, and there are currently very large FTS plants operating worldwide that produce liquid fuels and hydrocarbons from natural gas (NG) (gas-to-liquids, GtL process) and coal (coal-to-liquids, CtL process). Due to the limited availability of local biomass, the size of the BtL plants should be downscaled compared to that of a GtL or CtL plant. Since the feasibility of the XtL (X refers to any energy source that can be converted to liquid, including coal, NG, biomass, municipal solid waste, etc.) processes is strongly influenced by the economies of scale, the viability of small-scale BtL plants can be compromised. An interesting approach to overcome this issue is to increase the productivity of the FTS process by developing reactors and

*Corresponding authors: Ekain Fernandez, TECNALIA, Basque Research and Technology Alliance (BRTA), Mikeletegi Pasealekua 2, 20009 Donostia-San Sebastián, Spain, e-mail: ekain.fernandez@ tecnalia.com; and Sergio Rojas, Estructura y Reactividad, Institute of Catalysis and Petrochemistry (CSIC), Marie Curie 2, 28049 Madrid, Spain, e-mail: srojas@icp.csic.es

Dalia Liuzzi and José Luís G. Fierro: Estructura y Reactividad, Institute of Catalysis and Petrochemistry (CSIC), Marie Curie 2, 28049 Madrid, Spain. https://orcid.org/0000-0002-2754-3510 (D. Liuzzi)

Susana Perez: TECNALIA, Basque Research and Technology Alliance (BRTA), Leonardo da Vinci 11, 01510 Miñano, Spain

Enrique Ipiñazar, Amaya Arteche, Jose Luis Viviente and David

Alfredo Pacheco Tanaka: TECNALIA, Basque Research and

Technology Alliance (BRTA), Mikeletegi Pasealekua 2, 20009

Donostia-San Sebastián, Spain catalysts with higher productivities to generate the desired product fraction. Recently, by integrating membrane reactors with the FTS process the gas feeding and separation unit have been demonstrated in a single reactor. In this review, the most significant achievements in the field of catalytic membrane reactors for the FTS process will be discussed. Different types of membranes and configurations of membrane reactors, including $\mathrm{H}_{2} \mathrm{O}$ separation and $\mathrm{H}_{2}$-feed distribution, among others, will be analyzed.

Keywords: biofuel production; Fischer-Tropsch; membrane reactor; membranes; separations.

\section{Abbreviations}

$1 G / 2 G$ biofuels 1 st/2nd generation biofuels

BtL Biomass-to-liquid

CMSMs Carbon molecular sieve membranes

CNF

CtL

Carbon nanofiber

Coal-to-liquid

FBR Fluidized bed reactor

FTS

GHG

Fischer-Tropsch Synthesis

Greenhouse gases

GHSV Gas hourly space velocity

GtL

$\mathrm{HC}$

HT-FTS

HVOs

LT-FTS

LPG

MR

OCM

PBR

PBMR

Gas-to-liquid

Hydrocarbons

High-temperature FTS

Hydrotreated vegetable oils

Low-temperature FTS

Liquified petroleum gas

Membrane reactor

Oxidative coupling of methane

Fixed or packed bed reactor

PM

Packed bed membrane reactor

Particulate matter

PSD

SBCR

SoA

TOS

WGS
Pore size distribution

Slurry bubble bed column reactor

State-of-the-art

Time on stream

Water-gas shift 
$\mathrm{XtL}$ $\mathrm{X}$ refers to any energy source that can be converted to liquid, including coal, natural gas, biomass, municipal solid waste, etc.

\section{Introduction}

The transportation sector is among the most important primary energy consumers in the world, with a primary energy consumption of approximately $21 \%$ (86 EJ/y), originating mostly from fossil fuels. According to the European Energy Agency, in 2017, 27\% of the total EU-28 greenhouse gas emissions originated from the transport sector (i.e. road, aviation and maritime). Therefore, stringent actions are being implemented to replace fossil fuels. By 2020, the EU aims to have $10 \%$ allocation of the transport fuel of every EU country originating from renewable sources, such as biofuels, and this allocation is expected to be increased to $14 \%$ by 2030 . Although the EU aims to achieve the decarbonization of the transport sector via electrification methods, liquid hydrocarbon-based fuels will dominate the transportation sector market by 2030 with diesel increasing its utilization ratio over gasoline (Tosti et al. 2008). This feature is even more critical for the maritime and aviation sectors, since biofuels are the only feasible option to replace fossil-based fuels in the short term. As a result, there will be a deficit of the available biofuels, mostly diesel and kerosene, which poses a risk for the energy supply security of the EU.

Currently, there are no commonly agreed upon criteria used to define advanced biofuels; however, in general, advanced biofuels include cellulosic ethanol, butanol, methanol (MeOH), dimethyl ether (DME), Fischer-Tropsch diesel, drop-in fuels, and biofuels made from algae. Second-generation $(2 \mathrm{G})$ biofuels are commonly considered to be biofuels derived from nonfood feedstocks. These biofuels can be classified in terms of the processes used to convert the biomass to fuel: biochemical or thermochemical (Figure 1).

Thermochemical biomass conversion involves processes at much higher temperatures and generally higher pressures than those found in biochemical conversion systems. The key characteristics distinguishing thermochemical biofuels from biochemical biofuels are the flexibility in feedstocks that can be accommodated to the thermochemical processes and the fuels that are produced. Moreover, the thermochemical production of biofuels begins with gasification or pyrolysis. Gasification is generally more capital-intensive, but the final product is a clean finished fuel that can be used directly in engines or as a raw material for the production of fuels and chemicals. When the biomass source is far from the gasification unit (typically $>200 \mathrm{~km}$ ), it should be treated locally to increase its energy density, thus reducing transportation (and other logistical) costs. The most suitable treatments

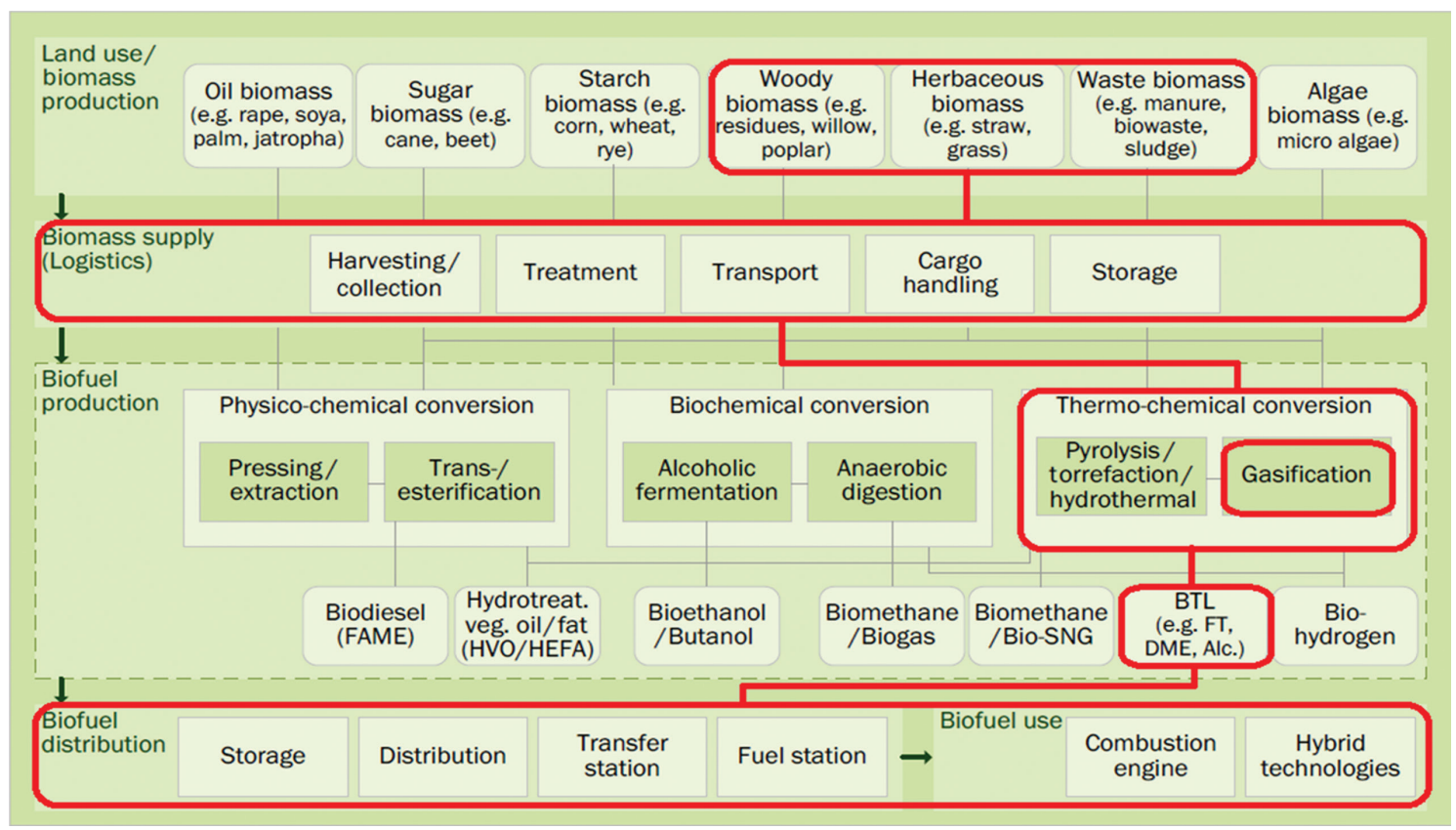

Figure 1: BtL production routes.

The Fischer-Tropsch-based route is indicated in red. Adaptation from DBFZ 2015 (Müller-Langer et al. 2013). 
are size reduction, (fast) pyrolysis or torrefaction (Dahmen et al. 2012, Ptasinski 2016).

Currently, there are nine operational advanced biofuel plants at the commercial scale in the EU for hydrotreated vegetable oil, $\mathrm{MeOH}$ and ethanol production (Flach et al. 2015). Although the biomass-to-liquid (BtL) process offers one of the highest greenhouse gas (GHG) saving potentials, the economy of the process, primarily the very large initial investment of a gas-to-liquids (GtL) plant, hinders the construction of commercial-sized BtL plants. However, several commercial-scale plants have been commissioned in recent years. Thus, Kaidi (n.d.) is planning to scale up a $\mathrm{BtL}$ plant to produce $2 \mathrm{G}$ biofuels via biomass gasification and Fischer-Tropsch synthesis (FTS) in Finland; in addition, Velocys (n.d.) is planning to construct a biorefinery in Mississippi to produce diesel, jet fuel, naphtha and waxes from waste. The Red Rock Biofuels project involves the construction of a new biofuel plant at Lakeview, Oregon, USA, and the associated infrastructure is set to produce jet fuel, diesel fuel and naphtha from woody biomass that is primarily mill and forest residues.

Due to the local availability of biomass and the large costs associated with biomass pretreatment and transportation, the capacity of BtL plants should be lower than that of commercial GtL or coal-to-liquids (CtL) plants. The future of BtL and Waste-to-Liquid plants pivots around the development of small-scale facilities capable of being competitive with production capacities below $2500 \mathrm{bbl} /$ day (Maitlis and de Klerk 2013). Reducing the capacity of the plant negates the principle of the economies of scale and thus jeopardizes the profitability of small-scale plants; however, small-scale plants can benefit from features such as significantly lower initial capital investments (lower financial risks) and the environmental aspects associated with the use of clean raw materials, i.e. biomass and/or waste. A possible method to avoid the economies of scale is to decrease the complexity of the BtL plants by removing, for instance, the carbon loop (recycling). This can be achieved by increasing the productivity of the FTS process by improving its single pass efficiency via increasing the conversion and selectivity to the desired product fraction and reducing the $\mathrm{CH}_{4}$ production. A further advantage of small-scale FTS plants is the possibility of modularity. The development of small-scale FTS plants has been pursued by several companies, including Syntroleum, Sasol and ENI (Deshmukh et al. 2011). Velocys is probably the most active company involved in developing innovative reactors for small-scale FTS plants. Velocys exploited the concept of process intensification by developing highly active catalysts to enhance the productivity of their fixed-bed reactors and to reduce the size, weight and cost of the chemical processing equipment. Simultaneously, Velocys realized that FTS is a highly exothermic reaction (releasing approximately $140-160 \mathrm{~kJ} / \mathrm{mol}$ CO converted), thus limiting the FTS conversion, that is, limiting the reactor productivity. Velocys addressed this issue by developing microchannel reactors, which have very efficient heat transfer rates, and this resulted in improved temperature control, allowing the microchannel reactors to operate at close to isothermal conditions and generate higher productivities (Jarosch et al. 2008, Deshmukh et al. 2010). For further information concerning this research, the reader is directed to the following works.

Catalytic membrane reactors are a type of catalytic reactor that can result in process intensification by selectively removing or feeding products or reactants, respectively. These reactors can or have been applied to processes such as $\mathrm{H}_{2}$ production and purification, $\mathrm{MeOH}$ production or hydrocarbon production from syngas. In this review, we analyze the different types of membrane reactors published in the literature in which the production of hydrocarbons from syngas has been demonstrated.

\subsection{Biofuel synthesis through biomass gasification (BtL)}

The use of biofuels is a suitable option for reducing GHG emissions while increasing the renewable energy allocation and mitigating the liquid fuel import demand. In addition, pure paraffinic biodiesel, such as that obtained from the BtL process, produces lower particulate matter emissions and reduces $\mathrm{CO}_{2}$ emissions compared to EU sulfurfree diesel (Lin et al. 2006). Among biofuels, the so-called synthetic diesel produced via the BtL process provides a feasible alternative to replace traditional fossil-derived fuels in diesel vehicles with carbon neutral transportation liquid fuels. A further advantage of the BtL process is the wide range of products that can be obtained (Lappas et al. 2011, Triantafyllidis et al. 2013). The composition of the syncrude (i.e. the mixture of products obtained from the FTS reactor) depends on the FTS technology used [high-temperature (HT)-FTS vs. ligh-temperature (LT)-FTS], but the composition always contains a mixture of gaseous, liquid (water or organic soluble) and solid fractions. These products can be used as fuels or chemicals. Depending on the refining process of the syncrude, a wide range of fuels can be obtained, including synthetic natural gas (NG), liquified petroleum gas (LPG), motor gasoline, jet fuel and diesel fuel. In addition, the lighter and heavier fractions can also be used to produce lubricants, paraffinic waxes and solvents, and commodities such as low chain olefins $\left(\mathrm{C}_{2-3}\right)$. 
The BtL process comprises several steps, including syngas production via biomass gasification, syngas cleaning and conditioning, syncrude production via the FTS process, and product upgrading and refining (Swain et al. 2011). The basic components for the BtL process are shown in Figure 2.

During the FTS process, the BtL process faces challenges similar to those of other synthetic fuels, such as CtL or GtL fuels. Due to the high capital costs, the economy of FTS plants improves by increasing the size of the plant. As a consequence, modern CtL and GtL plants reach fuel productions of more than 100,000 barrels per day (bpd) (Guettel et al. 2008).

On the other hand, although BtL processes essentially comprise the same steps as CtL or GtL processes, several important features should be considered. First, the "local" availability of biomass for BtL processes is significantly lower than that of or coal for GtL or CtL processes, respectively. Moreover, costs and emissions associated with biomass transportation are very high. As a result, the size (and complexity) of the BtL plants should be scaled down to be adaptable to local biomass availability. To reduce the risks associated with the economies of scale and the harvesting and transport of biomass, BtL plants should be scaled down to production levels of $<2000 \mathrm{bpd}$. This reduced production results in a significant reduction in plant complexity and catalyst use. To be economically feasible, the BtL plant productivity should be maximized, among other features, by increasing the conversion and selectivity toward $\mathrm{C}_{5+}$ hydrocarbons (provided diesel and waxes are the target products); this productivity target can only be achieved through the integration of a more productive reactor with advanced catalysts. The product distribution from the FTS process depends on the operating conditions [LT vs. HT, gas hourly space velocity (GHSV), P and syngas composition] and catalyst used. In the LT-FTS process (either with Co- or Fe-based catalysts), more than $66 \%$ of the hydrocarbon $(\mathrm{HC})$ compounds produced are within the $\mathrm{C}_{11-22+}$ range (mostly composed of linear paraffins); in addition, there are approximately $5-6 \% \mathrm{C}_{1}$ hydrocarbons produced, approximately $5-6 \% \mathrm{C}_{2-4}$ hydrocarbons produced and $22 \% \mathrm{C}_{5-10}$ hydrocarbons produced. The off-gas, containing $\mathrm{H}_{2}$, $\mathrm{CO}$ and lower alkanes, can be recycled by reconverting $\mathrm{C}_{1-4}$ to syngas, or the off-gas can be purged to a combined cycle for electricity production. The $\mathrm{C}_{5-10}$ fraction can be used as a raw material or as an upgrade for gasoline or jet fuel (De Klerk 2011). The high-molecular-weight fraction can be hydrocracked to increase the diesel fraction. It is noted that the final properties and weight fraction of the diesel obtained during the FTS process depend on the process itself; however, more importantly, the final properties and weight fraction depend on the downstream refining process.

\subsection{Biomass gasification and syngas cleaning/conditioning}

Gasification is a key technology for the use of biomass. Gasification offers a high flexibility to use different kinds of feedstocks, including biogenic residues of the forestry, agriculture and food industries (Gallucci et al.2015). These feedstocks are converted by a thermochemical process into syngas. From this syngas, all kinds of energy or energy carriers can be obtained. Steam is the gasification agent used that maximizes the yield of $\mathrm{H}_{2}$-rich syngas and minimizes the content of heavy hydrocarbons, detrimental impurities and tar (Rapagnà et al. 2000). Advanced, cost-effective, and highly efficient processes and systems are required to promote gasification and take full advantage of its potential. Fluidized bed gasification shows the feasibility of small- to medium-scale gasification plants because of its superior flexibility in relation to feedstock size and properties, and these characteristics of a gasification plant are often required to preferentially utilize local biomass resources and limit transportation costs and emissions (Bridgwater 1995).

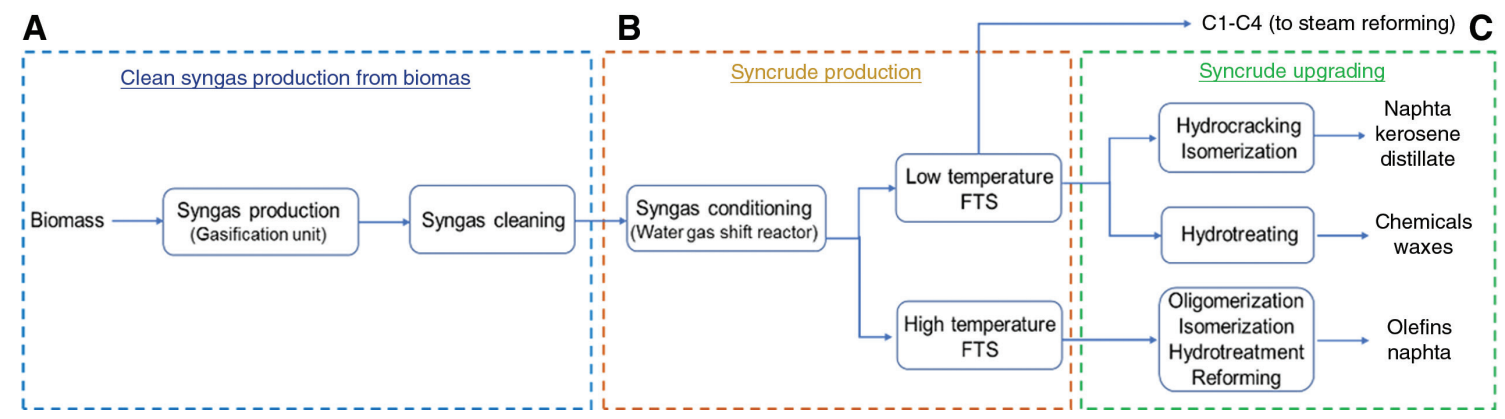

Figure 2: The BtL process steps.

(A) syngas production, (B) syncrude production and (C) syncrude upgrading. 
Regarding syngas cleaning, the concepts of process integration and combination are essential to enable higher efficiencies and better gas quality and purity at lower costs. In existing gasification plants, the downstream abatement of particulate (char and fly ash) and tar content of the raw syngas is normally performed by filtration and scrubbing after the recovery of its sensible heat (Hofbauer and Knoef 2005). However, any further reforming treatment required for syngas conditioning would be poorly integrated with the gasification unit, since a large amount of water vapor in the raw gas stream is condensed and lost during the process. In addition, such a process configuration does not allow high conversion efficiencies (Rabou et al. 2009). In this sense, a novel concept has been recently developed that integrates gasification, gas cleaning and conditioning into one reactor based on the utilization of catalytic ceramic filter candles inserted in the freeboard of the gasifier (Foscolo 2012). A mean tar conversion of $95 \%$ was obtained during the preliminary application of this concept, and methane and ethane reformed, with catalytic candles inserted in the freeboard of an industrial gasifier (Nacken et al. 2009), where solid particles were fully removed from the raw syngas.

Once the produced syngas is cleaned, the $\mathrm{H}_{2} / \mathrm{CO}$ ratio needs to be adjusted to the desired value (depending on the target refinery products) in a water-gas shift (WGS) unit. For instance, the $\mathrm{H}_{2} / \mathrm{CO}$ ratio of approximately 1.9 is the optimum value for improving the production of the diesel fraction (high alpha) in the LT-FTS process with Cobased catalysts (Zennaro et al. 2013).

\subsection{Fischer-Tropsch process for syncrude production}

The FTS process is a catalytically driven polymerization process whereby $\mathrm{CO}$ and $\mathrm{H}_{2}$ are transformed into a pool of hydrocarbons (syncrude) comprising gas, liquid and solid fractions (see Equation 1) (Fischer and Tropsch 1923). The FTS process is currently implemented at the commercial scale for the production of hydrocarbons from syngas derived either from coal via gasification (CtL) or from NG via reforming $(\mathrm{GtL})$.

$$
\mathrm{CO}+\left(1+\frac{m}{2 n}\right) \mathrm{H}_{2} \rightarrow \frac{1}{n} \mathrm{C}_{n} \mathrm{H}_{m}+\mathrm{H}_{2} \mathrm{O}(\mathrm{FTS}) \Delta H_{\mathrm{FTS}}=-165 \mathrm{~kJ} / \mathrm{mol}
$$

$\mathrm{CO}+\mathrm{H}_{2} \mathrm{O} \rightleftarrows \mathrm{CO}_{2}+\mathrm{H}_{2} \quad(\mathrm{WGS}) \quad \Delta H_{\mathrm{WGS}}=-41.3 \mathrm{~kJ} / \mathrm{mol}$

As observed from Equation 1, the FTS process is a highly exothermic reaction in which hydrocarbons and $\mathrm{H}_{2} \mathrm{O}\left(\mathrm{H}_{2} \mathrm{O}\right.$ is the most abundant product of the FTS process) are the only products. Due to the presence of $\mathrm{H}_{2} \mathrm{O}, \mathrm{H}_{2}$ and CO, the WGS reaction (Equation 2) can also occur (especially with Fe-based catalysts). As stated above, a pool of hydrocarbons from $\mathrm{C}_{1}$ (methane) to high-molecularweight hydrocarbons $\left(\mathrm{C}_{50}\right)$ are formed. Moreover, depending upon the reaction conditions, oxygenates (mostly alcohols, but a minor fraction of acids and ketones can be formed) and aromatic compounds (especially during HT-FTS) can also be formed. The Anderson-Schulz-Flory product distribution indicates that the chain growth probability $(\alpha)$ decreases with the number of atoms in the chain. Figure 3 shows the typical weight fraction vs. the $\alpha$ distribution during the FTS process.

Even though the FTS process leads to a broad distribution of HCs, the product distribution during the FTS process can be adjusted to maximize the production of the desired fraction by controlling the reaction conditions (P, $\mathrm{T}$ and GHSV), reactor type and catalyst composition. It is noted that a combination of all those factors, rather than one factor alone, allows product selectivity to be controlled at the industrial scale.
A

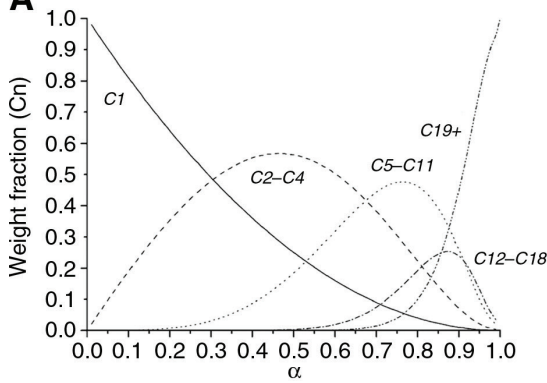

B

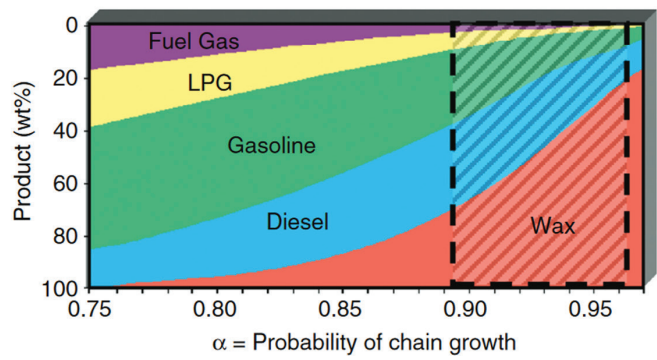

Figure 3: The selectivity to interest products fractions, e.g. gasoline, jet fuels. gasoline ( $C 5-\mathrm{C} 18)$, are limited to $<50 \%$. (A) Different representations of hydrocarbon production vs. chain growth probability. (B) Image from Boyer et al. (2016). 
The FTS process operates under two different regimes. The HT-FTS process operates at $300-350^{\circ} \mathrm{C}$ with fused iron-based catalysts and is used for the production of gasoline and low-molecular-weight olefins. The on-specification motor gasoline from FTS syncrude is not fundamentally different from the motor gasoline produced from crude oil, and the gasoline from the FT syncrude can thus be distributed using the same infrastructure. Currently, the only two industrial FTS refineries that produce motor gasoline are in South Africa at the PetroSA (Mossgas) facility in Mossel Bay and at the Sasol Synfuels facility in Secunda (De Klerk and Maitlis 2013). The properties of the gasoline produced at Sasol Synfuels and the fuel specifications defined in Europe are presented in Table 1.

The LT-FTS process operates at $200-240^{\circ} \mathrm{C}$ with ironor cobalt-based catalysts used for maximizing the production of the high-molecular-weight fraction (high $\alpha$ ). The LT-FTS process is used for the production of the diesel fraction, since the fraction of distillate and waxes is superior to that of the HT-FTS. Approximately $50 \%$ of the HC pool produced is paraffinic $\mathrm{C}_{22+}$ compounds (or $>66 \% \mathrm{C}_{11+}$ ) with very low contents of olefins, oxygenates and aromatics. As a consequence, a very clean diesel with a high cetane number and superior combustion characteristics can be obtained. Table 2 compares the selected properties of BtL vs. diesel and $1 \mathrm{G}$ biodiesel fuels. Further properties can be found in the literature (De Klerk 2007, 2011, Gill et al. 2011).

Tests performed on heavy duty trucks showed decreased emissions of HC, CO, NOx (reduced by 13\%) and PM (reduced by $26 \%$ ). A significant reduction in the GHG index is also reported for the BtL process compared to the CtL process at 0.06 vs. 1.79 , respectively. Compared with $1 \mathrm{G}$ biodiesel, the BtL diesel has a higher energy density and exhibits qualities closer to the specifications of fossil fuel-derived diesel, allowing higher blending percentages for conventional diesel engines.

Table 1: Motor gasoline properties of industrial FTS facilities in relation to the fuel specifications in Europe.

\begin{tabular}{lrl}
\hline & $\begin{array}{r}\text { Sasol } \\
\text { Synfuels }\end{array}$ & European EN228:2008 \\
\hline Research octane number & 93 & $95 \mathrm{~min}$ \\
Motor octane number & 83 & $85 \mathrm{~min}$ \\
Density $\left(\mathrm{kg} / \mathrm{m}^{3}\right)\left(\mathrm{at} 15^{\circ} \mathrm{C}\right)$ & 729 & $720-725$ \\
Sulfur content $(\mathrm{mg} / \mathrm{kg})$ & & 50 max. (until 2008-12-31) \\
Alkene content $(\% \mathrm{~V} / \mathrm{V})$ & 30 & 18 max. \\
Aromatic content $(\% \mathrm{~V} / \mathrm{V})$ & 29 & $35 \max$. \\
\hline
\end{tabular}

Table 2: Comparison of properties between the BtL diesel, diesel and $1 \mathrm{G}$ biodiesel (reprinted from Ogunkoya and Fang 2015, copyright 2015, with permission from Elsevier).

\begin{tabular}{lrrr}
\hline Properties & Diesel & 1G biodiesel & BtL diesel \\
\hline Density $\left(\mathrm{kg} / \mathrm{m}^{3}\right)$ & $820-860$ & & 780 \\
Energy content $(\mathrm{LHV})(\mathrm{MJ} / \mathrm{kg})$ & 43.1 & 37.9 & 43.9 \\
Flash point $\left({ }^{\circ} \mathrm{C}\right)$ & 74 & $>130$ & - \\
Autoignition temperature $\left({ }^{\circ} \mathrm{C}\right)$ & 315 & 149 & - \\
Dynamic viscosity $(\mathrm{Pa} \mathrm{s})$ at $25^{\circ} \mathrm{C}$ & 1.99 & 4.12 & 2.097 \\
Cetane number & 46 & 55.4 & $>70$ \\
Surface tension $(\mathrm{mN} / \mathrm{m})$ & 27.4 & 29.3 & 24.9 \\
\hline
\end{tabular}

\subsection{Upgrading of FTS syncrude}

To obtain useful/commercial products, the syncrude must be transformed via upgrading and refining. The importance of these steps cannot be underestimated, since this is where the value addition occurs during the FTS process. The design of the FTS refinery units depends on the nature of the syncrude (HT-FTS vs. LT-FTS) and of the targeted refinery products. The refinery should be designed to cope with the actual commercial specifications of the desired fuel, which are subject to political decisions and hence are different in different regions.

The FTS process allows for the production of a range of hydrocarbon products (syncrude), targeted $\mathrm{C}_{5+}$ hydrocarbons, mostly linear paraffins rich in diesel (i.e. $\mathrm{C}_{12}-\mathrm{C}_{23}$ ) and waxes (i.e. $\mathrm{C}_{23}$ ).

To increase the diesel yields, heavy hydrocarbons are hydrocracked over a metal-supported catalyst (typically $\mathrm{Pt}$ or $\mathrm{Ni}$ ), and the final products are distilled, rendering diesel as the main product and naphtha and LPG (Lødeng et al. 2013). The downstream processing of the FTS products is an energy-intensive part of the FTS plant due to the high temperatures $\left(-370^{\circ} \mathrm{C}\right)$ and $\mathrm{H}_{2}$ pressures $(\sim 5 \mathrm{MPa})$ required. Hydrocracking reactors are usually designed as a trade-off between maximum wax conversion and minimum yield of lighter products (i.e. naphtha and LPG). Temperature is an important factor in determining this trade-off, since hydrocracking heavier hydrocarbons typically requires higher reaction temperatures $\left(>370^{\circ} \mathrm{C}\right)$, while lighter FTS fractions may be converted to light olefins under such harsh conditions. In addition, the catalyst properties (i.e. catalyst type, loadings, and particle sizes) that are optimal for converting heavier fractions are different from the catalyst properties needed to convert lighter fractions. Heavier fractions are more reactive than lighter olefins, and the mass transport of hydrogen toward the catalyst active sites will 
play a greater role in the conversion of the heavier fractions than in that of the lighter olefins. In turn, adjusting the process conditions, such as the hydrocracking temperature or the catalyst packing properties according to the FTS process fraction, is essential to maximizing the diesel yield. Nevertheless, given the unavoidable distribution of products in the FTS syncrude, adjusting the process conditions cannot be achieved in a single conventional reactor.

Due to the low $\alpha$ value (ranging between 0.65 and 0.70) and, therefore, the high $\mathrm{C}_{5-10}$ naphtha production, the HT-FTS process is the preferred technology for maximizing motor gasoline. To maximize the production of gasoline, lighter and heavier hydrocarbons are refined to increase the fraction of hydrocarbons in the naphtha boiling range. The $\mathrm{C}_{3-4}$ fraction is oligomerized with solid phosphoric acid. Due to the high olefin content, the $\mathrm{C}_{5}$ fraction has a high octane number of approximately 95 , so it can be used in motor gasoline. The $\mathrm{C}_{6}$ fraction can be hydroisomerized, and it can also be refined to aromatic compounds using non-acidic Pt/L-zeolite. Heavier fractions are usually hydrotreated and hydroisomerized. The comprehensive details concerning the refinery design of an FTS plant can be found in the references (De Klerk 2007, 2011).

\section{Catalysts for the FTS reaction}

\subsection{Active metals for the FTS}

The most active metals for the FTS process are Fe, Co and $\mathrm{Ru}$, with $\mathrm{Ru}$ being the most active metal. $\mathrm{Ru} / \mathrm{Al}_{2} \mathrm{O}_{3}$ and $\mathrm{Co} /$ carbon nanofiber have metallic particles of approximately 9 and $6 \mathrm{~nm}$ (their optimum sizes), respectively, and the specific rates for the FTS reaction with these compounds were reported to be approximately $0.145 \mathrm{~s}^{-1}$ (Carballo et al. 2011) and $0.013 \mathrm{~s}^{-1}$ (Den Breejen et al. 2009), respectively. The " $\alpha$ " values, i.e. the chain growth probability, follow a similar trend; in general, $\mathrm{Ru}$ catalysts lead to a higher fraction of distillate and waxes. However, features such as metal particle size, promoter properties and metal support and reaction conditions (P, T, GHSV and time on stream) also affect the $\alpha$ value. State-of-the-art CtL and GtL plants use large amounts of catalyst, on the order of hundreds of tons (approximately $500 \mathrm{t}$ of Co and 2.5 $\mathrm{t}$ of Pt or Re in a 100,000 $\mathrm{bbl} / \mathrm{d}$ GtL plant). As a consequence, Fe- and Co-based catalysts are the only catalysts used at the industrial level.

Nevertheless, the interest in Ru as a catalyst for "small" FTS plants, such as those proposed for BtL processes, has recently increased due to the higher conversion per pass, higher $\alpha$ value and higher tolerance to $\mathrm{H}_{2} \mathrm{O}$ of the $\mathrm{Ru}$ based catalysts. It should be noted that when using $\mathrm{Ru}$, the precious metal could be $99 \%$ recycled from the spent catalyst, reducing the total cost of the plant and reducing the environmental impact of mining. This is also true for Co-based catalysts.

\subsubsection{Iron-based catalysts}

Fused iron catalysts are used in the HT-FTS process for the production of short-chain hydrocarbons. Precipitated Fe catalysts are used in the LT-FTS process for the production of high-molecular-weight hydrocarbons. Recently, Synfuels China erected an FTS plant that operates at a medium temperature (approximately $275^{\circ} \mathrm{C}$ ) using slurry reactors with $\mathrm{Fe}$-based catalysts that have high $\alpha$ values (Xu et al. 2015). Iron carbides, most likely the Hägg carbide $\left(\chi-\mathrm{Fe}_{2.5} \mathrm{C}\right)$, are the actual active phases for the FTS process (CO dissociation); however, the actual nature of the carbide remains elusive (Herranz et al. 2006). When compared under similar reaction conditions, Fe-based catalysts are less active (per site) and have lower $\alpha$-values for the FTS process than Co- or Ru-based catalysts. Fe catalysts are very active for the WGS reaction (Equation 2); therefore, $\mathrm{Fe}$ is suitable when poor quality syngas is fed into the FTS reactor. However, high amounts of $\mathrm{CO}_{2}$ (up to $50 \%$ selectivity) are produced during the FTS process with Fe catalysts.

\subsubsection{Cobalt-based catalysts}

Co-based catalysts are used in the LT-FTS process with syngas obtained from NG to obtain high-molecular-weight hydrocarbons (i.e. diesel fraction and waxes). Due to the high price of $\mathrm{Co}$, catalysts are usually prepared as nanosized Co particles that are deposited onto inorganic supports with high surface areas. It is widely accepted that Co-metallic surfaces are the active phases for the FTS process. The optimum Co particle size is approximately $6 \mathrm{~nm}$ (Den Breejen et al. 2009). The synthesis of Co-based catalysts comprises several steps, including impregnation of the support with a Co precursor, calcination that produces $\mathrm{CoO}$ (and/or $\mathrm{Co}_{3} \mathrm{O}_{4}$, depending on the Co loading) and subsequent reduction to $\mathrm{Co}^{\circ}$. Nevertheless, the reduction of $\mathrm{CoO}$ is difficult, and the fraction of unreduced $\mathrm{CoO}$ could be $50 \%$ (or higher). In addition, large cobalt particles are formed when subjected to high reduction temperatures. 


\subsubsection{Ruthenium-based catalysts}

$\mathrm{Ru}$, especially when deposited on rutile $\mathrm{TiO}_{2}$, is the most active catalyst for FTS, leading to the highest $\alpha$ values (Carballo et al. 2011). Sergio Rojas et al. tested a B-doped $\mathrm{Ru} / \mathrm{TiO}_{2}$ catalyst for FTS in a $\mathrm{H}_{2}$-packed bed membrane reactor (PBMR) concept. $\mathrm{Ru} / \mathrm{TiO}_{2}$ is a very stable catalyst for the FTS process, since CO dissociation occurs only at terrace sites via the $\mathrm{H}$-assisted pathway instead of at the step-edge sites, which is responsible for the high initial FTS activity observed in the $\mathrm{Ru} / \mathrm{TiO}_{2}$ catalysts (Liuzzi et al. 2016b). Ru can also be used as a promoter of Feor Co-based catalysts. Due to its high price and scarcity, $\mathrm{Ru}$ is not used commercially. $\mathrm{Ru}^{0}$ is the active phase for the FTS reaction. The effect of the support is vital for the activity of Ru catalysts, and CO conversion rates of 150$800 \mu \mathrm{mol}_{\mathrm{CO}} / \mathrm{g}_{\mathrm{Ru}} / \mathrm{s}$ are reported for $\mathrm{Ru} / \gamma-\mathrm{Al}_{2} \mathrm{O}_{3}$ and $\mathrm{Ru} / \mathrm{TiO}_{2}$.

\subsection{Role of promoters}

Oxides of $\mathrm{K}, \mathrm{Cu}$, light transition metals ( $\mathrm{Mn}$ and $\mathrm{Mg}$ ) or lanthanides $\left(\mathrm{La}_{2} \mathrm{O}_{3}\right.$ and $\left.\mathrm{CeO}_{2}\right)$ and actinides $\left(\mathrm{ThO}_{2}\right)$ are typical promoters for the FTS reaction with Fe-based catalysts. K is the most important promoter, as it neutralizes acid sites (hydrogenolysis) and blocks sites for hydrogenation. K also increases the propagation probability and enhances CO dissociation. To promote active phase reduction, promoters, such as $\mathrm{Cu}, \mathrm{Re}, \mathrm{Ag}$, Au or Pt, are used. Sasol's commercial Co catalysts are promoted with Pt (0.05\%) or $\mathrm{Re}$, whereas Ru catalysts usually do not contain promoters (De Klerk and Maitlis 2013).

\subsection{Support properties}

Moderate-high surface area oxides, such as $\gamma-\mathrm{Al}_{2} \mathrm{O}_{3}$ and $\mathrm{SiO}_{2}$, are the most commonly used materials; however, the use of $\mathrm{ZrO}_{2}, \mathrm{TiO}_{2}$, zeolites, silica-alumina, carbonaceous materials and clays has also been reported (Storsæter et al. 2005, González Carballo et al. 2011). In principle, the support should allow for good metal dispersion $(D \geq 10 \%)$ and avoid strong interactions with the metal phase, which will result in the formation of very stable mixed oxides (Co or Ru oxides) with the support (Iglesia et al. 1992). The concentration of acid sites should be low enough to avoid secondary reactions (cracking and/ or isomerization of $\mathrm{C}_{5+}$ ). The use of acidic supports, such as zeolites or silica alumina, is not recommended for the production of straight long-chain paraffins, since acidity from the support enhances the production of short-chain hydrocarbons. In fact, the acid groups of $\gamma-\mathrm{Al}_{2} \mathrm{O}_{3}$ are partially neutralized (by thermal treatments) prior to catalyst synthesis. Other properties include high thermal stability for support regeneration treatments and high strength and mechanical resistance.

\subsection{Poisoning and deactivation}

Catalyst poisoning can occur due to poisons introduced with the feed and can damage the catalytic performance. $\mathrm{S}$ - and N-containing species should be completely removed from the syngas feed. $\mathrm{H}_{2} \mathrm{~S}: \mathrm{H}_{2}$ ratios as low as 20-30 ppb decrease the activity of the FTS catalysts by three to four orders of magnitude. The presence of halogenated compounds also decreases the activity of the FTS catalysts. Several causes of catalyst deactivation have been observed (Bartholomew 2001). Among these causes, the formation of waxes and inactive carbons that block access to active sites are the most significant occurrences of catalyst deactivation (Mukkavilli et al. 1986). Regeneration via thermal treatment is possible. Co-based catalysts are more tolerant than Fe-based catalysts. The deactivation by oxidation of the active Co nanoparticles during the FTS reaction is also well established in the literature (Fischer et al. 2014, Tsakoumis et al. 2017, Wolf et al. 2017).

\section{Membranes for the Fischer-Tropsch reaction}

Two types of membranes are mainly used to improve the performance of conventional Fischer-Tropsch reactors. On the one hand, water separation membranes can selectively remove $\mathrm{H}_{2} \mathrm{O}$ molecules (the most abundant product from the FTS reaction) from the reaction chamber. As a result, the equilibrium is shifted toward the production of hydrocarbons, i.e. higher conversions can be attained. On the other hand, distributed feeding membranes, that is, membranes selective for $\mathrm{H}_{2}$ or $\mathrm{CO}$, can be used to control the concentration of the reactants along the reactor axis; they can be used to maintain a constant $\mathrm{H}_{2} / \mathrm{CO}$ ratio, which avoids unfavorable reactions, such as methane formation, and controls heat production in the FTS reaction (Rohde et al. 2005b).

\subsection{Membranes for water removal}

The permeation properties of a membrane are quantified using permeability and selectivity, which will depend on 
the membrane material and the operating conditions. Membranes for water vapor permeation can be classified into polymeric and inorganic membranes. Polymeric membranes are not suitable for the FTS process because they have a low temperature resistance; in addition, the organic compounds generated in the reaction could produce swelling, which decreases the selectivity, blocks the pores and decreases the permeation.

Inorganic membranes, such as silica, zeolite and carbon molecular sieve membranes (CMSMs), have been used for water gas separation. In addition, these membranes possess a unique anti-swelling feature at high feed water concentrations and organic compounds. Silica is one of the most attractive membranes, but it is not chemically stable in water and alkaline solutions. The well-defined pore size and the hydrophilic properties of zeolites make them promising materials for water removal. The concept of a zeolite membrane reactor for the hydrogenation of $\mathrm{CO}_{2}$ to $\mathrm{MeOH}$ has been proposed by several groups [for instance, see Gorbe et al. (2018) and references therein], showing a high capacity for water removal. However, to the best of our knowledge, there is a lack of studies actually showing the role of the zeolite membrane reactor during the production of hydrocarbons or alcohols. In addition, zeolite membranes are expensive, and membranes without defects (mainly the spaces between the zeolite crystals) are very difficult to prepare (Kosinov et al. 2016). Therefore, in most cases, the obtained selectivities are in the range of Knudsen diffusion.

On the other hand, CMSMs have been considered the next generation of membrane technology (Llosa Tanco and Pacheco Tanaka 2016). In contrast to polymeric membranes, CMSMs present a unique feature of anti-swelling at high concentrations of feed water and organic compounds and high thermal and chemical stability (Okamoto et al. 1999, Xu et al. 2012). CMSMs are produced by the carbonization of a polymeric precursor under an inert atmosphere or vacuum. CMSMs have a unique microporous structure, which allows them to discriminate gas molecules by size and shape (Salleh and Ismail 2015). The gas separation performance of carbon membranes depends on the pore size and pore size distribution (PSD). The main feature of CMSMs is that their PSD and hydrophilicity can be tailored to suit a desired application. The pores in carbon membranes are formed by packing imperfections between ordered regions in the material, and the pores are described as slit-like with an idealized bimodal PSD. The distribution consists of larger pores with sizes of $0.7-2 \mathrm{~nm}$ (known as micropores or galleries) connected by smaller pores with sizes $<0.7 \mathrm{~nm}$ (known as ultramicropores). The larger sized micropores provide higher permeation and sorption sites for strongly absorbable molecules, which simultaneously decreases the passage of less adsorbing molecules (adsorption diffusion mechanism). Moreover, ultramicropores are responsible for the separation by the molecular sieving mechanism, where only molecules with a smaller size than the pore will permeate. The combination of these two transport mechanisms provides the high permeability and selectivity characteristics of these materials (Ismail and David 2001). The majority of the CMSMs reported in the literature are prepared by carbonization at temperatures higher than $750^{\circ} \mathrm{C}$ with the objective of obtaining graphitized carbon structures, which form the pores. Depending on the polymer used, at that temperature, most of the functional groups are removed, which gives the pores a hydrophobic character; hydrophobic gases could be trapped in the pores, which considerably reduces the gas permeation. For water-selective membranes, the micropores should be hydrophilic.

The most common configuration of carbon membranes is tubular. Since permeation through membranes depends on the thickness and the partial pressure difference, very thin membranes (selective layer less than $5 \mu \mathrm{m}$ ) are required. Supported CMSMs are prepared by carbonizing thin polymer precursors on porous supports. Henis and Tripodi (1981) stated that it is rather difficult to achieve an adequate thin layer without pinholes when coating a porous support. Thus, several dipping-dryingcarbonization cycles are required to obtain carbon membranes without defects.

For the first time, Pacheco Tanaka and Llosa Tanco reported the preparation of a 3- $\mu \mathrm{m}$-thick defect-free supported composite alumina-CMSM made from cheap polymer phenolic resin precursors [resol (Teixeira et al. 2011, 2012) and novolac (Llosa Tanco et al. 2015a,b)] on alumina tubes (200 nm pore size) in a one-dip-dry carbonization cycle (Figure 4A, B). Llosa Tanco et al. also reported that the pore size and PSD and the pore hydrophilicity of the alumina-CMSM were adjusted by changing the carbonization temperature of the membrane. At carbonization temperatures in the range of $450-700^{\circ} \mathrm{C}$, the pores were hydrophilic. Figure $4 \mathrm{C}$ shows the gas permeance of various gases as a function of the kinetic diameter and temperature obtained by Tecnalia and TUE in the HyGrid project. It can be observed that the gas permeance increases as the gas decreases in size owing to the molecular sieving mechanism of permeation. Since the kinetic diameter of water is smaller than $\mathrm{H}_{2}(0.26$ and $0.29 \mathrm{~nm}$, respectively), and it can be strongly adsorbed on hydrophilic pores (such as those developed at Tecnalia), it is expected that the water permeance will be higher than that of $\mathrm{H}_{2}$. Very recently, this assumption was confirmed 
A

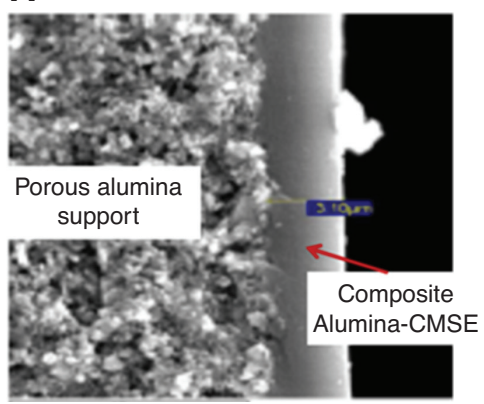

B

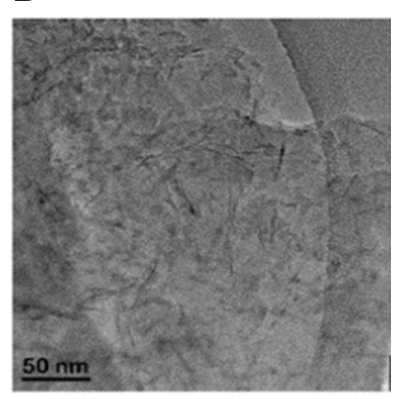

C

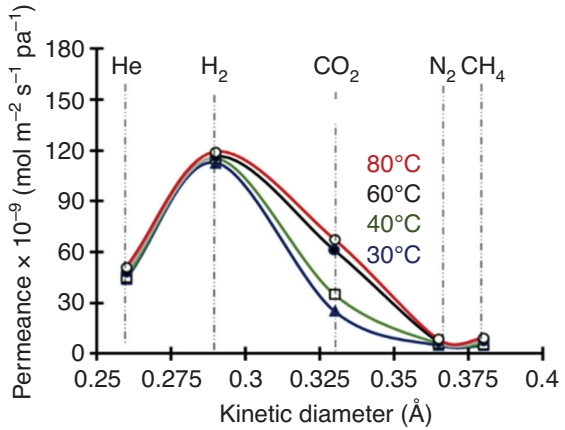

Figure 4: Alumina-CMSM.

(A) SEM image showing the selective layer and the porous alumina support (reprinted from Llosa Tanco et al. 2015b, copyright 2015, with permission from Elsevier), (B) HRTEM images of the composite alumina-CMSM (Llosa Tanco et al. 2015b), (C) permeance of an aluminaCMSM as a function of the kinetic diameter of the gases and the temperature (nonpublished results from HyGrid).

using water permeation tests performed with an aluminaCMSM at Tecnalia in the MALTA Project (n.d.). The $\mathrm{H}_{2} \mathrm{O}$ permeance obtained at $250^{\circ} \mathrm{C}$ for a membrane carbonized at $600^{\circ} \mathrm{C}$ was $\sim 1.3 \times 10^{-6} \mathrm{~mol} \mathrm{~m}^{-2} \mathrm{~s}^{-1} \mathrm{~Pa}^{-1}$, which is approximately eight times higher than that for $\mathrm{H}_{2}\left(\sim 1.6 \times 10^{-7} \mathrm{~mol}\right.$ $\left.\mathrm{m}^{-2} \mathrm{~s}^{-1} \mathrm{~Pa}^{-1}\right)$. These results suggest that carbon molecular sieve membranes can be a good alternative for water removal in FTS membrane reactors.

The separation of water molecules from hydrocarbons by the use of zeolite membranes has also been studied by Aoki et al. (2000). These authors characterized type A zeolite membranes prepared by hydrothermal synthesis on a porous $\alpha-\mathrm{Al}_{2} \mathrm{O}_{3}$ tube. They studied the separation of water from different compounds, including hydrocarbons, between 35 and $200^{\circ} \mathrm{C}$. Hydrocarbon chains longer than $\mathrm{C}_{2} \mathrm{H}_{6}$ did not permeate through the membrane. In addition, the affinity of $\mathrm{H}_{2} \mathrm{O}$ molecules for zeolitic and nonzeolitic pores reduced the permeability of hydrophobic permeates.

\subsection{Hydrogen-selective membranes}

Hydrogen separation membranes may be classified into the following categories depending on the type of membrane materials (Gallucci et al. 2013): polymeric membranes, porous membranes, dense metal membranes and proton conducting membranes.

Microporous ceramic membranes are promising materials for high-purity hydrogen production and separation. However, these membranes separate hydrogen by size exclusion; thus, selectivity is still limited compared to dense inorganic membranes.

To obtain high-purity hydrogen permeate streams, dense metal membranes (mainly palladium alloys) and dense ceramic membranes are currently the most suitable materials due to their high hydrogen selectivity. The proton conducting membranes operate at $>600^{\circ} \mathrm{C}$; thus, it is not possible to integrate them in FTS reactors (at $200-300^{\circ} \mathrm{C}$ ). On the other hand, Pd-based alloys usually function at moderate temperatures $\left(300-500^{\circ} \mathrm{C}\right)$ and are good candidates for FTS reactors. Hydrogen permeation through Pd-based membranes follows a solution-diffusion mechanism (Eichenauer 1967). The most important problem associated with the use of pure Pd membranes is the hydrogen embrittlement phenomenon. Performing FTS operations with hydrogen at a temperature below $300^{\circ} \mathrm{C}$ and a pressure below $2 \mathrm{MPa}$ leads to the nucleation of the $\beta$-hydride phase from the $\alpha$-phase, resulting in severe lattice strains. In this case, a pure palladium membrane becomes brittle after a few $\alpha \leftrightarrow \beta$ cycles (Hsieh). The use of palladiumsilver alloy membranes can suppress this embrittlement phenomenon when working at temperatures lower than $300^{\circ} \mathrm{C}$ (Okazaki et al. 2006), which would be the operating temperature for the FTS reaction.

Another important problem is palladium surface poisoning caused by sulfur compounds (Peters et al. 2016), $\mathrm{CO}$ (Murmura and Sheintuch 2018), $\mathrm{H}_{2} \mathrm{O}$, chlorine, carbon, unsaturated hydrocarbons, etc. (Gallucci et al. 2013). Some of these species are present in the FTS reaction, which affects the performance of the Pd-based membranes and, subsequently, the FTS membrane reactor.

As in the case of CMSMs described in Section 3.1, since permeation through palladium-based membranes depends on the thickness and the partial pressure difference, very thin membranes (selective layers less than 5 $\mu \mathrm{m})$ are required. The selection of the support is of critical importance in the preparation of thin and defect-free palladium membranes. High surface roughness and the presence of large pores inhibit the deposition of thin palladium membranes. Asymmetric porous ceramic supports, exhibiting a gradual reduction in pore size from the bulk 
to the top layer, present a good surface quality to support very thin Pd-based membranes; however, the asymmetric porous ceramic supports are fragile. Currently, the commercially available ceramic supports are asymmetric tubes and capillaries/hollow fibers. Metallic supports are more robust than ceramic supports; however, the commercially available metallic supports, which are mainly tubular, have large pores, the PSD is not uniform, and the surface quality is too low to be directly used as supports for very thin Pd membranes. For membranes in which both the selective layer and the support are metallic and that operate above the Tamman temperature (i.e. half the melting point temperature), interdiffusion of both metals occurs, reducing the permeation performance of the membrane (Mardilovich et al. 1998). To solve this problem and to improve the quality of the surface, an intermetallic diffusion barrier layer is deposited between the metallic support and the metallic selective layer (Fernandez et al. 2016).

More specific information about palladium-based membranes and their applications can be found elsewhere (Yun and Oyama 2011, Gallucci et al. 2013, Arratibel Plazaola et al. 2017, Rahimpour et al. 2017, Peters and Caravella 2019).

\section{Membrane reactors for the Fischer-Tropsch reaction}

FTS is a complicated exothermal three-phase process. The gas phase reactant molecules have to dissolve into the two-phase products (gas and liquid) before contacting the surface of the solid catalyst particles. In addition, the products should evaporate into the gas phase to vacate the catalyst bed. The mass transport within the flooded catalyst particle is much slower than that in the case of a two-phase process due to lower diffusivities in the liquid phase.

Many investigations have been performed to increase hydrocarbon production and decrease $\mathrm{CH}_{4}$ and $\mathrm{CO}_{2}$ formation during this FTS process. Accordingly, the main research efforts being undertaken are the synthesis and modification of new catalysts and changes in the FTS reactor configuration (Saeidi et al. 2014a,b).

At the industrial scale (CtL and GtL processes), three main types of reactors are erected in FTS plants (Dry 2002, Bartholomew and Farrauto 2006, 2011): fixed- or packedbed reactors (PBRs), fluidized bed reactors (FBRs) and slurry bubble bed column reactors (SBCRs) (see Figure 5) (Guettel et al. 2008, Jess and Kern 2009, Saeidi et al. 2014a,b, 2015).

In PBRs, the catalyst is fixed, and there is no need for a subsequent catalyst separation stage. It is also easier to scale up this type of reactor from a tube on the laboratory scale to a pilot plant on a commercial scale. Nevertheless, the main problem of conventional PBRs is the removal of the produced heat by the FTS reaction. This problem can be solved by a multitubular reactor configuration that includes a cooling system between the tubes. The catalyst bed is placed inside the tubes, and the syngas enters from the top of the reactor in a plug-flow regime. The (cooling) water circulates in the shell side of the reactor to prevent the reactor from overheating.

In FBRs, a fluid is fed to the reactor and passed through the catalyst particles at high enough velocities to suspend the catalyst so that it behaves as a fluid. The particle size used in FBRs is usually on the order of hundreds of nanometers, while in packed-bed reactors, the particle size is larger than $1 \mathrm{~mm}$.

SBCRs are composed of a vertical vessel where the three phases are in contact: the gas reactant injected at
A

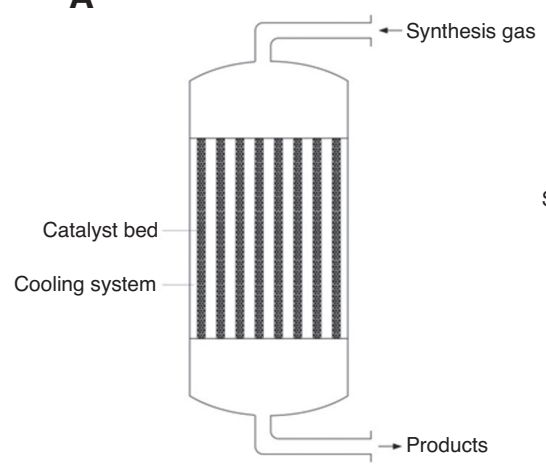

B

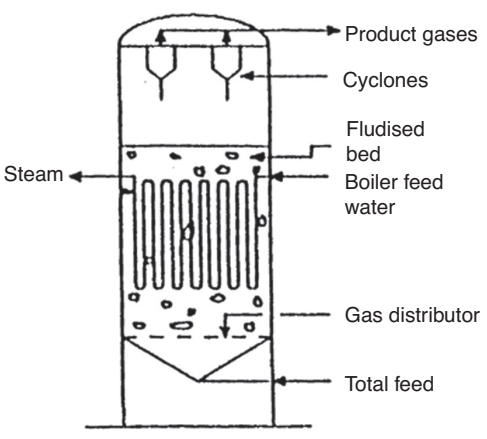

C

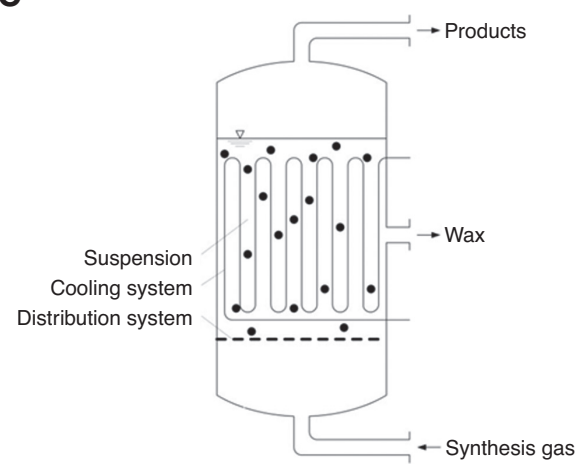

Figure 5: Main types of FTS reactors.

(A) multitubular packed/fixed-bed reactor (PBR), (B) fluidized bed reactor (FBR) (reprinted from Dry 2002b, copyright 2002, with permission from Elsevier), (C) slurry bubble column reactor (SBCR) (Guettel et al. 2008). 
the bottom of the reactor is in contact with the liquid phase of the products where the solid catalyst is in suspension. An internal heat-exchanger tube (bundle-type) with medium steam generation pressure allows heat extraction to occur. The gas products are evacuated at the top of the column, and the liquid/solid phase is laterally withdrawn. The catalyst is dispersed in heavy oil that is bubbling up through the slurry. An SBCR allows excellent heat removal and thus higher productivities, and it has the capacity to produce $17,000 \mathrm{bbl} /$ day (or higher) of products.

FBRs are categorized as high-temperature FischerTropsch reactors, and they are not suitable for producing liquid-phase products because they may cause catalyst agglomeration and fluidization loss (Saeidi et al. 2014b). FBRs, either fixed-bed or circulating-bed configuration, in which the entrained catalyst is continuously fed through a loop, allow for more efficient heat removal and high-temperature operation; in addition, they are used for obtaining short-chain olefins. On the other hand, PBRs and SBCRs are categorized as low-temperature Fischer-Tropsch reactors, and they are recommended for producing liquidphase products on an industrial scale (Saeidi et al. 2015).

A new class of small-scale and highly productive reactors has been introduced recently for small-scale FTS plants. Companies such as Rentech, Syntroleum, Eni, Velocys and CompactGTL have developed suitable fixedbed or slurry reactors for medium scales or distributed scales (Deshmukh et al. 2011). Due to their small size and modularity, microchannel reactors are a suitable option for addressing the challenges posed by the small-scale BtL process. Microchannel reactors have high capacity to remove the tremendous amount of heat released during the FTS reaction; therefore, it is possible to achieve high onepass conversions by using optimized $\mathrm{Co} / \mathrm{SiO}_{2}$-based catalysts. These reactors, which are commercialized by Velocys, are reported to increase catalyst productivity by $5-10$ times vs. using traditional slurry-bed and fixed-bed reactors.

However, neither conventional reactors completely solve the problems of heat (PBRs) nor mass transfer (SBCRs) (Atkinson 2010).

New concepts and different strategies are presently proposed to intensify the mass and heat transfer properties of multiphase reactors, such as innovative reactors based on membrane reactors and others, due to several disadvantages of industrial reactor systems (Guettel et al. 2008, Hashim et al. 2011).

The current industrial problem of the trade-off between the high concentration of the active component and limitations of diffusion could be solved by using several types of membrane reactors to enhance the product yield/selectivity and to thermodynamically shift the reactions toward the products.

Recent developments in different applications of membrane reactors at the laboratory scale for the FTS process have been reported in the literature (Khassin 2005, Rohde et al. 2005b, Unruh et al. 2010). The concept behind membrane reactors is to shift the chemical equilibrium toward the desired product by selectively feeding or removing one (or several) components. Hence, the motivations for utilizing membrane applications are the higher specific production rates, increased catalyst lifetimes, and increased product selectivities. Thus, membrane reactors may have great potential, especially for future small- or medium-scale FTS units, e.g. for offshore applications and BtL processes.

According to the functionality and properties of the membranes, they could play different roles in the FTS process. Four membrane reactor concepts for FTS have been reported in the literature (Rohde et al. 2005b, Guettel et al. 2008):

1. Distributed reactant feeding

2. In situ water removal

3. Forced-through-flow

4. Dual-bed membrane reactor

Other research groups classified catalytic membrane reactors according to the type of membrane (permselective or nonpermselective) and the catalyst location (inside or outside the membrane) (Tosti et al. 2008).

Figure 6 summarizes the published concepts for membrane applications in FTS reactors.

The concepts of the distributed feeding and water removal have been assessed using different reactor configurations, as summarized in Table 3.

\subsection{Distributed reactant feeding membrane reactor}

As membrane reactors allow the controlled addition of one of the reactants into the reaction zone, their use leads to improved selectivity and better temperature control by distributed feeding.

The membranes could be either nonpermselective or permselective. For nonpermselective membranes, the pure reactant is fed across the membrane at an adequate rate according to the membrane permeance. For the permselective membrane, a mixture of reactants is fed from one side of the membrane, and the reactant of interest permeates through the membrane; the chemical reaction is carried out on the other side of the membrane. 
A

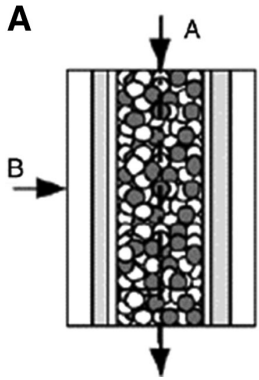

B

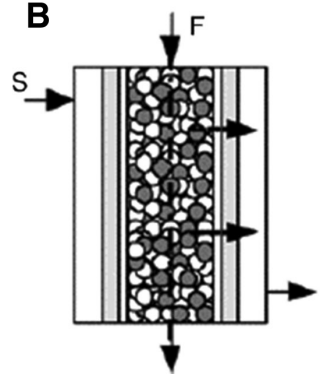

C

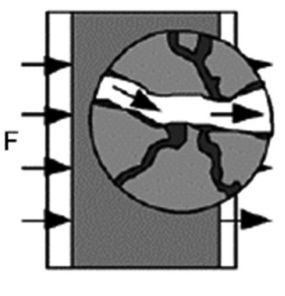

D

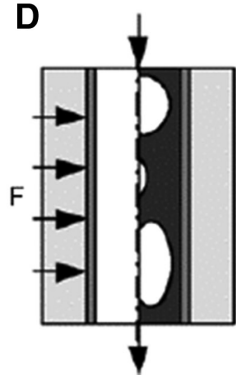

Figure 6: Membrane reactors for FTS proposed in the literature.

(A) distributed feeding of reactant $B$ through the membrane and reaction with reactant $A(A+B),(B)$ in situ $\mathrm{H}_{2} \mathrm{O}$ removal by a selective membrane (F, feed; S, sweep), (C) plug-through contactor membrane (PCM) with wide transport pores, (D) forced-through-flow membrane contactor, with product and heat removal by the circulated liquid product (reprinted from Rohde et al. 2005b, copyright 2005, with permission from Elsevier).

Table 3: Concepts of membrane applications in FTS reactors (reprinted from Rohde et al. 2005b, copyright 2005, with permission from Elsevier).

\begin{tabular}{|c|c|c|c|c|c|c|c|}
\hline $\mathrm{Nr}$ & Concept & Reactor & Memb./support & Catalyst & $\mathbf{x}_{\mathrm{co}}$ & $\mathrm{S}_{\mathrm{c2}}+$ & $\mathrm{Y}_{\mathrm{C} 2}+$ \\
\hline 1 (a) & Distributed feeding & $\begin{array}{l}\text { PBNMR } \\
\text { PBCMR }\end{array}$ & $\gamma-\mathrm{Al}_{2} \mathrm{O}_{3} / \alpha-\mathrm{Al}_{2} \mathrm{O}_{3}$ & $\begin{array}{l}\mathrm{Co} / \alpha-\mathrm{Al}_{2} \mathrm{O}_{3} \\
\mathrm{ZSM}-5 / \alpha-\mathrm{Al}_{2} \mathrm{O}_{3}\end{array}$ & $\begin{array}{l}+^{\mathrm{a}} \\
-\mathrm{b}\end{array}$ & $\begin{array}{l}-^{\mathrm{a}} \\
+^{\mathrm{b}}\end{array}$ & $\begin{array}{l}-^{\mathrm{a}} \\
+^{\mathrm{b}}\end{array}$ \\
\hline 1 (b) & Selective water removal & PBMR & $\begin{array}{l}\text { Mordenite/ZSM-5/silicalite/ } \\
\text { stainless steel }\end{array}$ & n.a. & & & \\
\hline 1 (b) & Selective water removal + reactant distribution & PBMR & $\mathrm{Si}(\mathrm{OH})_{\mathrm{x}} \mathrm{O}_{\mathrm{y}} / \gamma-\mathrm{Al}_{2} \mathrm{O}_{3} / \alpha-\mathrm{Al}_{2} \mathrm{O}_{3}$ & $\mathrm{Fe} / \mathrm{Al}_{2} \mathrm{O}_{3} / 5 \mathrm{~K} / \mathrm{Cu}$ & $t^{c}$ & & $+^{\mathrm{c}}$ \\
\hline 1 (b) & Selective water removal & PBMR & 4A-zeolite $/ \mathrm{TiO}_{2} /$ stainless steel & n.a. & & & \\
\hline $1(\mathrm{c} 1)$ & Forced-through-flow catalytic membrane & CNMR & Porous catalyst/copper structure & $\mathrm{Co} / \mathrm{Al}_{2} \mathrm{O}_{3}$ & + & + & + \\
\hline $1(c 2)$ & Forced-through-flow catalytic membrane & CNMR & Catalyst $/ \gamma-/ \alpha-\mathrm{Al}_{2} \mathrm{O}_{3}$ & $\mathrm{P} / \mathrm{Pt}-\mathrm{Co} / \mathrm{Al}_{2} \mathrm{O}_{3}$ & + & - & + \\
\hline
\end{tabular}

PBNMR, Packed bed nonpermselective membrane reactor; PBMR, packed bed MR; CMR, catalytic MR; CNMR, catalytic nonpermselective MR. ${ }^{\mathrm{a} C O}$ fed across membrane.

${ }^{\mathrm{b}} \mathrm{H}_{2}$ fed across membrane.

'Based on $\mathrm{CO}_{2}$.

Hydrogen-selective membranes used as distributors allow the control of the $\mathrm{H}_{2} / \mathrm{CO}$ ratio along the entire reactor length, so the optimal ratio is constant and unfavorable reactions are not promoted; thus, the selectivity of the process is enhanced. Moreover, this optimal $\mathrm{H}_{2} / \mathrm{CO}$ ratio allows better temperature control. In general, the distribution of hydrogen with membranes can be used to enhance the selectivity to long-chain products, since the $\mathrm{H}_{2} / \mathrm{CO}$ ratio remains constant along the reactor axis (Rohde et al. 2005b).

The commercialization of FTS technology is limited by features, such as selectivity toward the products of interest, catalyst deactivation and less-than-optimum thermal and carbon efficiency (Lu and Lee 2007), among other limitations. A good design of the reactor is a key factor for overcoming most of these issues, such as a reactor design to maintain an optimal and constant-through-flow of the catalytic bed $\mathrm{H}_{2} / \mathrm{CO}$ ratio.

Biomass-derived syngas is usually a $\mathrm{H}_{2}$-deficient syngas for the FTS process, i.e. the $\mathrm{H}_{2} / \mathrm{CO}$ ratio is well below the optimum value of 2 . Specifically, this ratio is 1 in woody biomass or black oil gasification-derived syngas (Brandberg et al. 2000, Ekbom et al. 2003). An external WGS unit is needed to adjust the $\mathrm{H}_{2} / \mathrm{CO}$ ratio to the stoichiometric value $\left(\mathrm{H}_{2} / \mathrm{CO}=2\right)$ prior to the FTS reaction unit in a BtL plant (Steynberg and Dry 2004). It is important to highlight that syngas production usually accounts for $50-70 \%$ of the total on-site capital cost of the process (Steynberg and Dry 2004, Rafati et al. 2017).

Thus, it is very important to research novel alternatives to conventional FTS reactors to increase the CO conversion and selectivity for desired products when $\mathrm{H}_{2}$-deficient syngas, such as that syngas produced from biomass, is fed.

The concept of distributed feeding applied to the FTS process is based on an individual supply of $\mathrm{H}_{2}$ and $\mathrm{CO}$ through a tubular membrane along the reactor axis. One of the reactants is fed through a tubular membrane, while the other reactant is fed through the catalyst bed located inside the membrane in a PBMR configuration. This FTS 
membrane reactor has been proposed to control the heat production of the reaction, since the activity and product selectivity depend significantly on the $\mathrm{H}_{2} / \mathrm{CO}$ ratio in the case of Co-based catalysts. Through this concept, it is possible to minimize the CO-depletion phenomenon in the catalyst bed and positively affect the gas phase composition in the feed. This concept can be realized by the integration of a highly $\mathrm{H}_{2}$-permselective membrane into the reaction compartment. The performance of this membrane reactor strongly depends on the membrane permeation properties.

Several groups (Guillou et al. 2004, Forghani et al. 2009, Elekaei et al. 2011) showed that the gasoline fuel yield must be increased by using a hydrogen-permselective membrane reactor. The reported results show the influence of the $\mathrm{H}_{2} / \mathrm{CO}$ ratio on product selectivity. With $\mathrm{CO}$ as the feed gas and $\mathrm{H}_{2}$ as the distributed reactant, the $\mathrm{H}_{2} / \mathrm{CO}$ ratio remains extremely high along the reactor axis. Hence, the inhibition of the FTS reaction rate due to CO remains low, and increased conversions were measured compared to the conversions measured in the conventional reactor. However, the formation of long-chain hydrocarbons is not favored, and $\mathrm{C}_{1}-\mathrm{C}_{4}$ hydrocarbons were mainly recovered as products due to the high inhibition of CO (i.e. poisoning).

The concept of $\mathrm{H}_{2}$ distribution feeding for FTS membrane reactors with $\mathrm{H}_{2}$-permselective thin Pd-Ag-based supported membranes and very active Ru-based catalysts has recently been demonstrated experimentally (Liuzzi et al. 2016a). Higher $\mathrm{C}_{5+}$ and lower $\mathrm{C}_{1}$ products were obtained with the $\mathrm{H}_{2}$-distributed membrane FTS reactor compared with a fixed-bed reactor working under the same experimental conditions (Figure 7). This result is very interesting, but the operating conditions should be considered to avoid possible membrane damage due to embrittlement at lower temperatures. This phenomenon can be suppressed by using Pd-Ag membranes with high Ag contents.

On the other hand, it was reported that wax formation in the reaction zone may reduce $\mathrm{H}_{2}$ permeation through the membrane due to its blockage, which consequently decreases the level of CO conversion over time. Other species, such as CO, may also have a negative effect on the membrane and membrane reactor performance.

\subsection{In situ water removal membrane reactor}

Extractive membranes can contribute to improving the FTS reaction yield by selectively removing water, which is the main byproduct, from the reaction. The presence of the produced water vapor is detrimental to the overall efficiency of the reaction. High water vapor partial pressure can lead to accelerated Fe and Co catalyst deactivation, increase the WGS activity, decrease the partial pressure of the reactants and minimize the residence time by dilution (Espinoza et al. 2000). Due to this effect, conventional FTS reactors present a relatively low $\mathrm{CO}$ conversion. $\mathrm{H}_{2} \mathrm{O}$ removal leads to the following advantages: increased reaction rates by the higher partial pressures, reduced byproduct formation, lower energy requirements, possible heat integration and higher catalyst lifetime.

The concept of in situ $\mathrm{H}_{2} \mathrm{O}$ removal can be realized by the integration of a highly permselective membrane into the reaction compartment, i.e. a slurry, packed or fluidized bed reactor. High driving forces across the membrane are
A

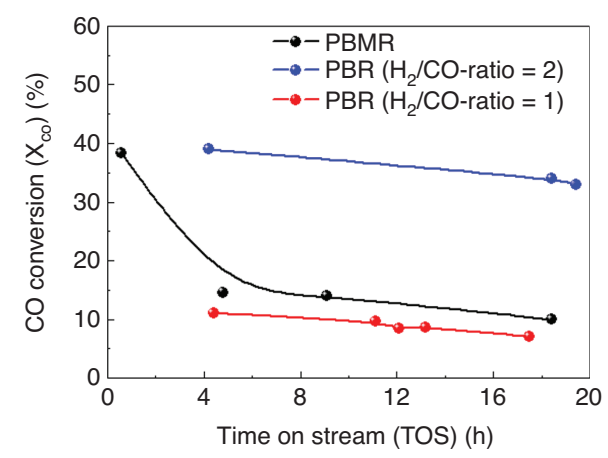

B

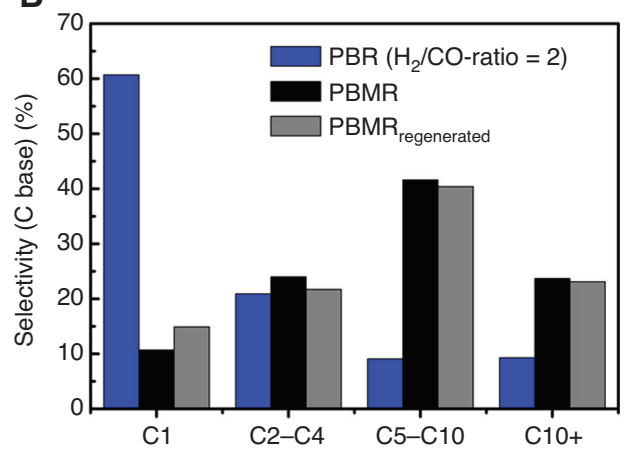

Figure 7: Higher $\mathrm{C}_{5+}$ and lower $\mathrm{C}_{1}$ selectivity is obtained with the $\mathrm{H}_{2}$-PBMR concept compared to a PBR. (A) $\mathrm{CO}$ conversion at $553 \mathrm{~K}$ vs. time on stream with a RuB1Ti catalyst in a PBMR $\left(\mathrm{H}_{2} \mathrm{CO}=1\right)_{\text {perm }}$ (black color) and regenerated (open circles), PBR with $\mathrm{H}_{2} / \mathrm{CO}=2$ (blue color) and $\mathrm{H}_{2} / \mathrm{CO}=1$ (red color), $\mathrm{P}=1 \mathrm{MPa}, \mathrm{GHSV}=7500 \mathrm{~mL}_{\mathrm{CO}+\mathrm{H}_{2}} / \mathrm{g}_{\text {cat }} / \mathrm{h}$ and $\Delta \mathrm{Pi}_{\mathrm{H} 2}=0.35 \mathrm{MPa}$. (B) Product selectivity for $\mathrm{PBR} \mathrm{H}_{2} / \mathrm{CO}=2$ (blue bars), PBMR (black bars) and PBMR after thermal regeneration (green bars) during the first hours of reaction. Reprinted from Boyer et al. 2016, copyright 2016, with permission from Elsevier. 
increased by a sweep gas at a high flow rate and decreased pressure. Reactor performance strongly depends on the permselectivity and hydrothermal and mechanical stability of the membrane (Rohde et al. 2005b). For in situ $\mathrm{H}_{2} \mathrm{O}$ removal, high $\mathrm{H}_{2} \mathrm{O}$ permeances and high permselectivities are essential for membrane applications (Rohde 2011). There are various references to in situ dehydration in FTS reactions.

One example is the U.S. Patent No. 6403660 (Espinoza et al. 2002). This patent describes the use of slurry or fluidized beds to produce hydrocarbons by the FTS reaction. In the case of the slurry bed, a water permselective membrane is placed in the slurry to remove the water that is produced. In the fluidized bed, a membrane for water removal is used inside the catalyst bed. This membrane removes water from the bed during the reaction, and a significant increase in conversion was reported [95.9\% of $\mathrm{H}_{2}+\mathrm{CO}$ conversion for the membrane removing $90 \%$ of the water in the reactor and $58.8 \% \mathrm{H}_{2}+\mathrm{CO}$ conversion for the conventional FTS reactor (without membranes)].

On the other hand, negative effects of water on ironand cobalt-based Fischer-Tropsch processes were discussed; thus, the selective extraction of water from the Fischer-Tropsch reaction has the potential to offer considerable advantages, such as higher production rates per reactor volume and longer catalyst lifetime due to better catalyst protection from reoxidation and mechanical degradation during operation.

Rohde et al. (2005a,b), Ronde et al. (2006) proposed a fixed-bed reactor with a silica membrane or a ceramic supported polymer (CSP) membrane with an iron catalyst. The use of an inert membrane packed bed reactor with a tetraethyl orthosilicate-coated ceramic membrane did not offer enough selectivity for water removal under FTS reaction conditions. This issue was improved using $\mathrm{H}_{2}$ or $\mathrm{H}_{2} /$ $\mathrm{CO}_{2}$ (3/1) as the sweep gas, but the total carbon conversion remained low.

In the U.S. patent No. 20090170964 by Chevron (Najafi et al. 2009), a fixed-bed membrane reactor is presented (Figure 8). The reactor is a packed bed with an integrated water-permselective membrane. The zeolite membrane used allows for the selective removal of the water produced from the reaction zone to be used as a permeate stream.

The pressure in the reaction zone is $5-40 \mathrm{bar}$, and the temperature is $180-220^{\circ} \mathrm{C}$ for cobalt-based catalysts and approximately $250-280^{\circ} \mathrm{C}$ for iron-based catalysts. The pressure within the inner membrane tube is maintained at a much lower pressure than that in the reaction zone where the FTS reaction takes place. The molar ratio of the syngas feed $\left(\mathrm{H}_{2} / \mathrm{CO}\right)$ is 2:1.

With the utilization of the membrane, the CO conversion is $10 \%$ higher than that of conventional reactors (Figure 9).

Rahimpour et al. (2011) developed a novel dual-type reactor concept for FTS reactions (Figure 10). This configuration is composed of a fixed-bed water-permselective hydroxy sodalite (H-SOD) membrane reactor and a fluidized bed hydrogen-permselective membrane reactor. The results obtained with this novel configuration show that the gasoline yield is higher than that of the conventional reactor. It has been reported that the H-SOD zeolite-like membrane exhibits a very high selectivity of water to hydrogen and good thermal and mechanical stability.

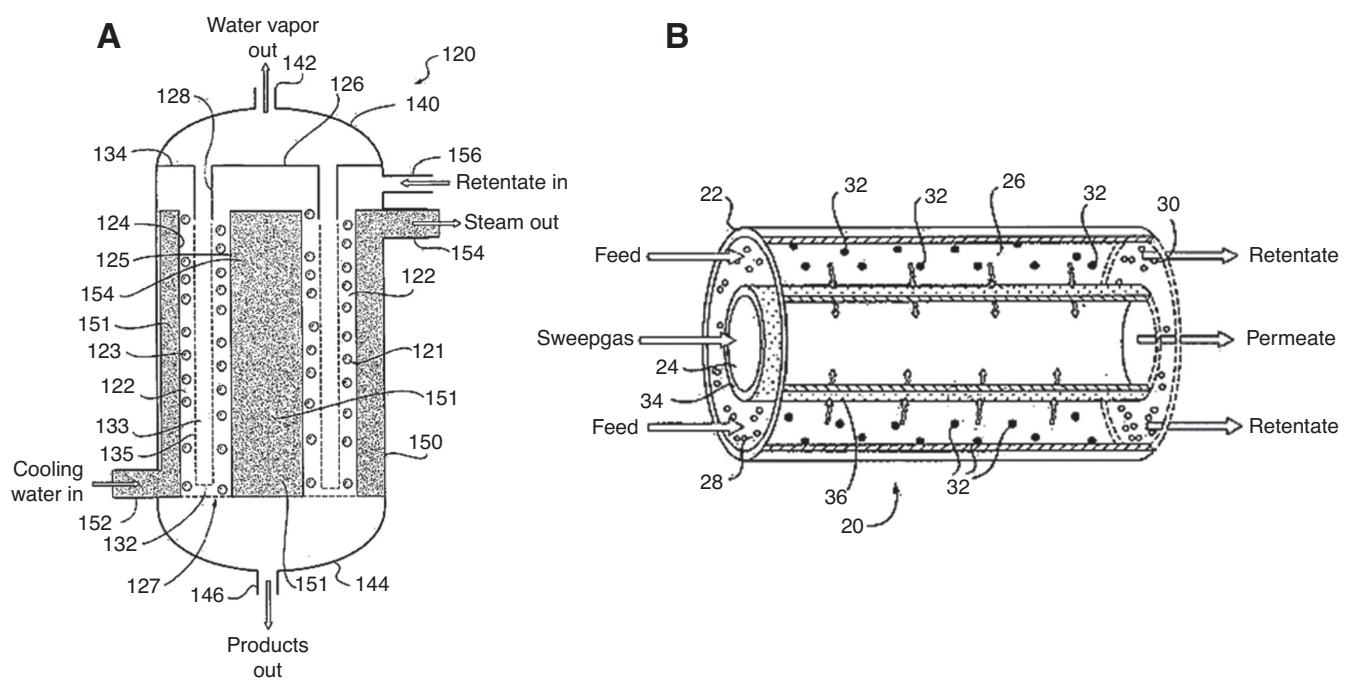

Figure 8: Packed bed membrane reactor by Chevron (Najafi et al. 2009). 


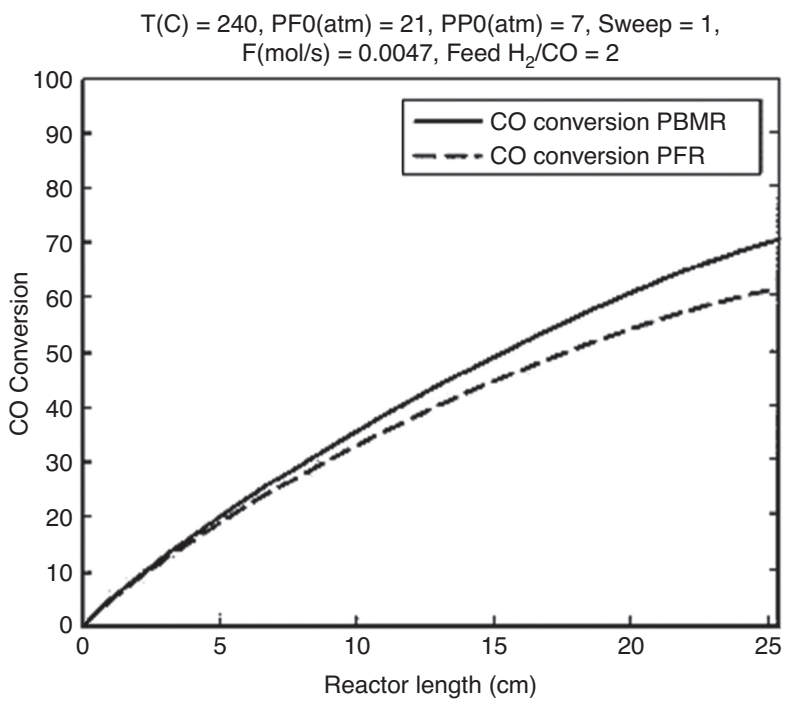

Figure 9: Comparison of $\mathrm{CO}$ conversion in a packed bed reactor with and without a membrane by Chevron (Najafi et al. 2009).

Energy research Centre of the Netherlands (ECN) has developed and patented a membrane reactor uniquely designed for sealing a membrane with the reactor shell (Figure 11). To fix the stainless steel parts to the membrane tube, compressed carbon gaskets are applied. With this system, high temperatures and a reducing atmosphere can be applied. The FTS reaction tests were carried out with a new CSP membrane provided by ECN (Rohde 2011). The experimental results of the FTS reaction demonstrate that the $\mathrm{CO}_{2}$ conversion and the hydrocarbon yield can be increased significantly by the application of a permselective hydrophilic membrane in combination with an active FTS catalyst. Furthermore, the $\mathrm{CO}_{2}$ conversion is accelerated with low $\mathrm{H}_{2} \mathrm{O}$ partial pressures because both the $\mathrm{CO}_{2} /$ $\mathrm{CO}$ shift and the FTS reaction rates are increased.

The use of membranes in the FTS process for removing water from the reaction zone has become more relevant in recent years due to the benefits it provides. Among others, the principal benefits are the acceleration of the reaction rate and the improvement in the catalyst life.

It seems that the zeolite membrane could be the selected membrane to fulfill this proposal, but other membranes, such as CMS, can be a good option. However, there are no commercially available membranes with sufficient high permeability, selectivity and stability for continuously removing water in an FTS process (Rohde et al. 2005b, Rohde 2011).
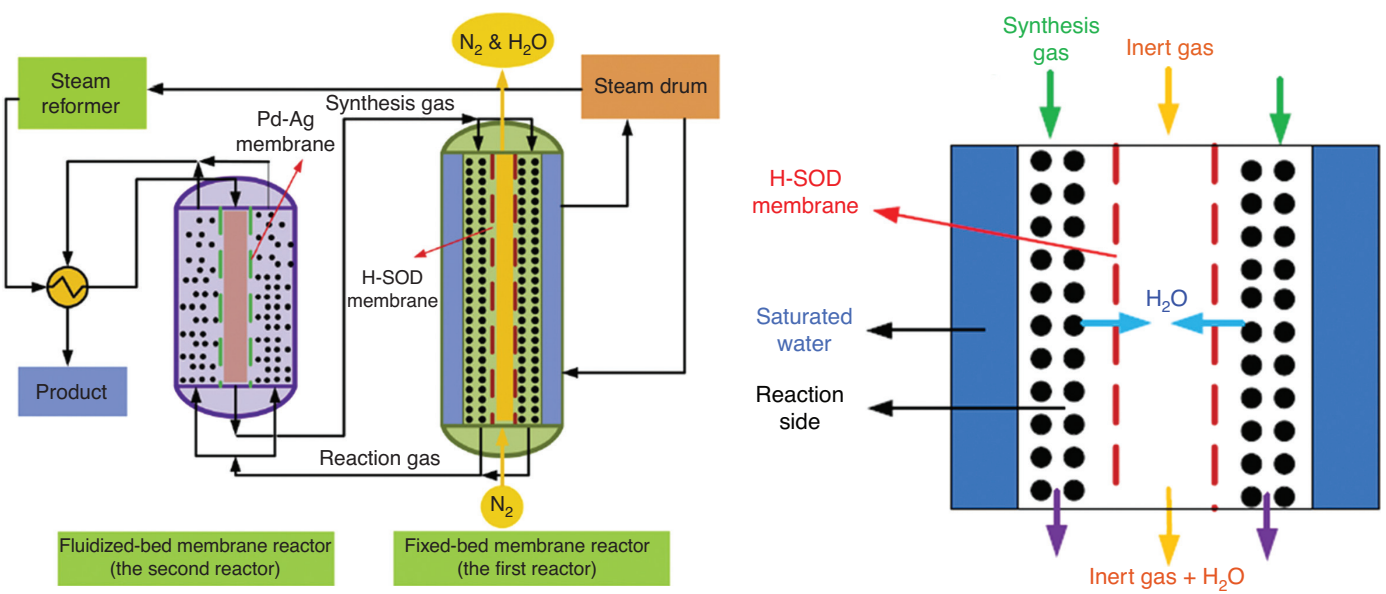

Figure 10: H-SOD membrane reactor for the FTS process (reprinted from Rahimpour et al. 2011, copyright 2011, with permission from Elsevier).

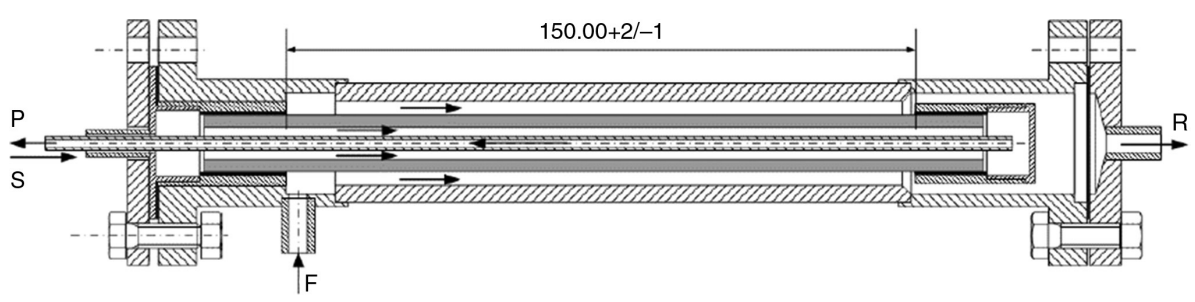

Figure 11: ECN membrane reactor (F, feed; R, retentate; S, sweep; P, permeate) (Rohde 2011). 
As discussed in Section 3.1, to date, there have been no successful results reported in the literature concerning the separation of water and hydrocarbons through membranes in the FTS process. In other reactions using membrane reactors for water removal, e.g. in the synthesis of methyl tert-butyl ether (MTBE) (Salomón et al. 2000), mordeniteand NaA-based membranes have been characterized to study the selectivity of $\mathrm{H}_{2} \mathrm{O}$ separation from the different hydrocarbons present in the reaction. In that work, it was observed that the separation selectivity is inversely proportional to the polarity of the studied molecules $[\mathrm{MeOH}$, tert-Butyl alcohol (TBA), MTBE, isobutylene (IB) and $\left.\mathrm{H}_{2} \mathrm{O}\right]$. Thus, the water separation selectivity at $90^{\circ} \mathrm{C}$ was $\mathrm{H}_{2} \mathrm{O} /$ $\mathrm{IB}>\mathrm{H}_{2} \mathrm{O} / \mathrm{MTBE}>\mathrm{H}_{2} \mathrm{O} / \mathrm{TBA}>\mathrm{H}_{2} \mathrm{O} / \mathrm{MeOH}$. However, when increasing the temperature by $10^{\circ} \mathrm{C}$, the selectivity toward water separation decreases.

\subsection{Forced-through-flow membrane reactor}

In the forced-through-flow concept, a pressure difference is applied across the catalytic membrane. The catalyst is incorporated in the porous structure of a membrane, and the reactants of the FTS reaction are generally forced through the membrane with a short contact time; thus, intensive mixing occurs in the pore system. In the literature, two different forced-through catalytic membrane reactor concepts for the FTS process were proposed (Bradford et al. 2005, Khassin 2005, Khassin et al. 2005).
The first concept is based on a mesoporous ceramic honeycomb monolith whose channels are coated with layers of a microporous ceramic membrane and an FTS catalyst (see Figure 12). The syngas is fed from the shell side and forced to flow through the membrane and catalyst layers. The membrane is impermeable to the produced hydrocarbons, which can be withdrawn from the tube side (Bradford et al. 2005).

The other approach addresses the problem of efficient heat removal and is based on using a catalytic membrane with high $\mathrm{Co} / \mathrm{Al}_{2} \mathrm{O}_{3}$ catalyst load and high thermal conductivity. The tubular catalytic membranes present a distinct three-modal pore distribution. Large pores $(3-7 \mu \mathrm{m})$ exist throughout the membrane and enable high permeation rates. The transport pores are interconnected by narrower pores that will be filled with the liquid product due to capillary forces. The feed gas stream is forced through the membrane either inward or outward in the radial direction (see Figure 13). The main advantages of the so-called plug-through contactor membranes (PCMs) are the high space-time yields under flat temperature profiles, the high selectivity toward heavy hydrocarbons and the high heat conductivity. However, the PCM concept has significant drawbacks, such as the large reactant streams that need to be recycled, the relatively low reactor volume to catalyst amount ratio and the difficulties in the exchange of the catalyst (Khassin 2005, Khassin et al. 2005).

In this kind of membrane reactor, high-molecularweight products are expected to fill the pores of the

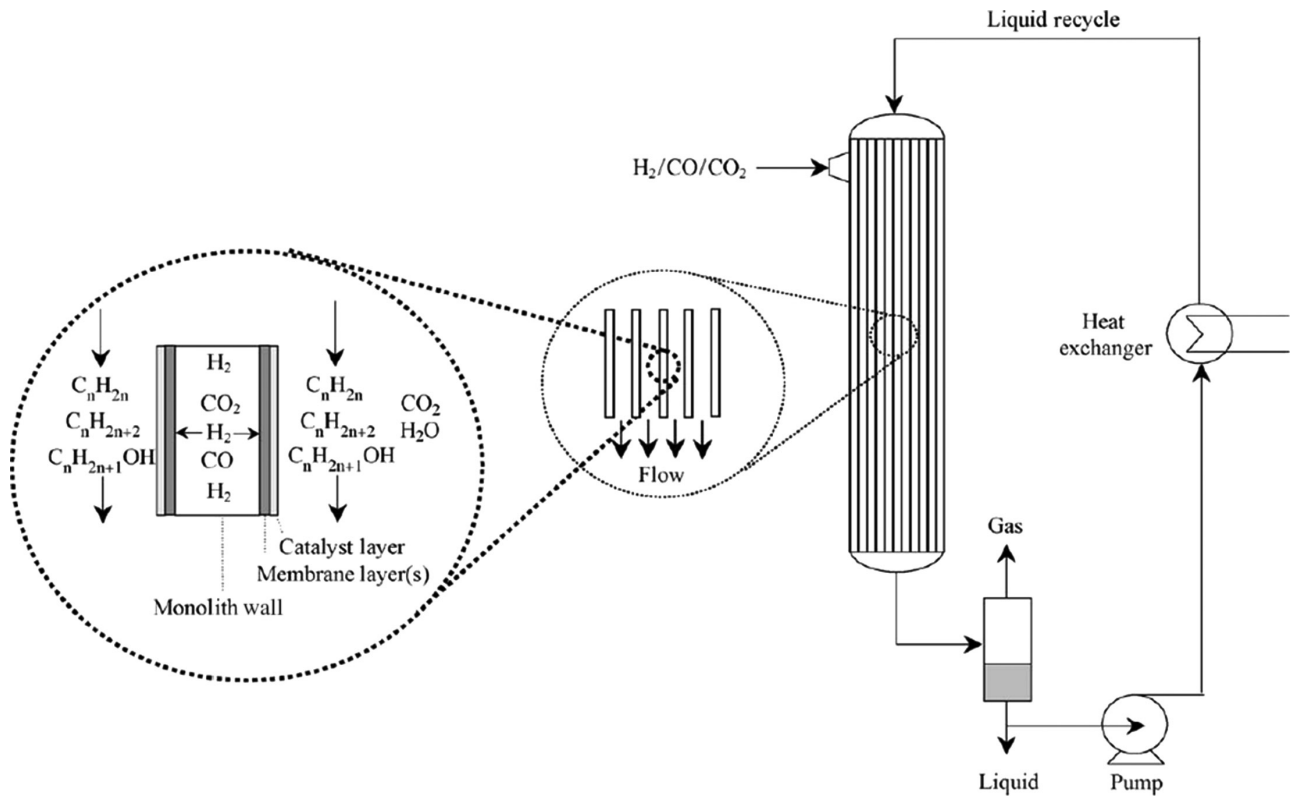

Figure 12: Monolith loop membrane reactor concept for the FTS process (reprinted from Bradford et al. 2005, copyright 2005, with permission from Elsevier). 


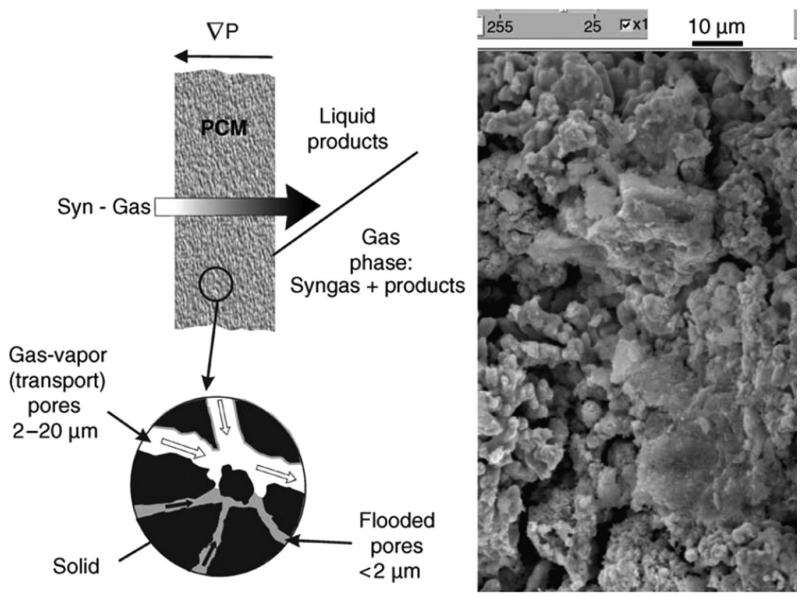

Figure 13: Scheme and SEM image of the pore-through contactor membrane (PCM) (reprinted from Khassin et al. 2005, copyright 2005, with permission from Elsevier).

membrane during the FTS reaction. Fritsch et al. (2004) proposed a periodic flow to purge the liquid products for isobutene dimerization in a flow-through membrane reactor.

\subsection{Dual-bed membrane reactors}

Several research groups have focused on the modeling and optimization of FTS using dual-bed reactors.

A novel dual-bed reactor strategy with a hydrogenpermselective membrane was proposed for FTS (see Figure 14). A dual-type reactor is a shell and tube heat exchanger reactor in which the first reactor, a watercooled reactor, is combined in series with the second reactor, a synthesis gas-cooled reactor. The cold feed synthesis gas is preheated inside the tubular membranes of

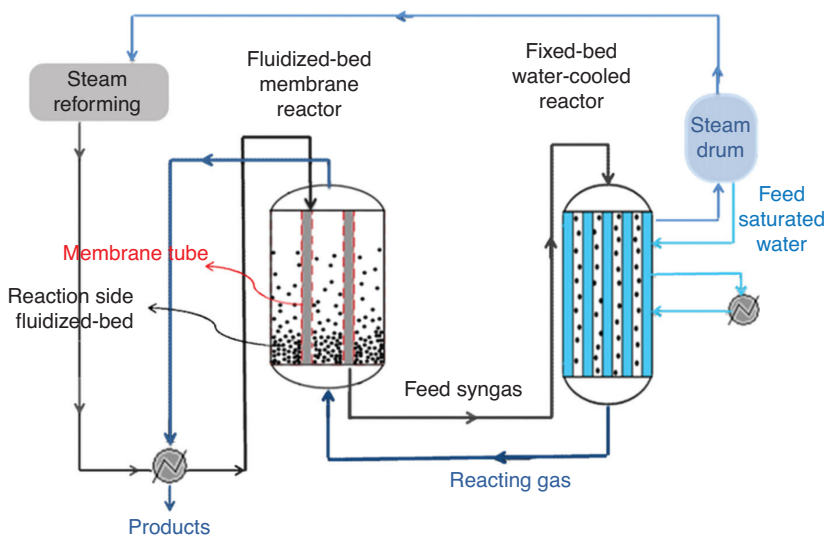

Figure 14: Scheme of a dual-type membrane reactor for the FischerTropsch synthesis process (reprinted from Rahimpour and Elekaei 2009, copyright 2009, with permission from Elsevier). the fluidized bed reactor and then fed into the tubes of the water-cooled reactor, which is an isothermal reactor, and the chemical reactions are initiated by the catalyst. In this stage, the synthesis gas is partly converted to hydrocarbons. The reacting gas leaving the water-cooled reactor is directed into the shell side of the gas-cooled reactor in countercurrent mode with the synthesis gas flowing inside the tubular membranes and the hydrogen permeating through the membrane to the shell side where the reactions are completed. According to the simulation results, the dual-type membrane reactor showed an increase of approximately $45 \%$ in the gasoline yield and a decrease in $\mathrm{CO}_{2}$ formation (which is an important environmental aspect) compared to the conventional fixed-bed reactor (Rahimpour and Elekaei 2009).

On the other hand, there is another approach in which two consecutive reactors are combined to convert methane to heavy hydrocarbons: one reactor is used for the oxidative coupling of methane (OCM) and the other reactor is used for the FTS reaction (Müller-Langer et al. 2013) (see Figure 15) (Ghareghashi et al. 2013a,b). In the OCM reactor, the synthesis gas and $\mathrm{C}_{2+}$ are produced and fed to the FTS reactor, where it converts $\mathrm{CO}$ and $\mathrm{H}_{2}$ to heavy hydrocarbons. In this second FTS reactor, hydrogen-selective membranes are included to allow the continuous addition of hydrogen to the FTS reaction medium. Simulations were performed to compare a fixed-bed reactor with a membrane reactor for the FTS reaction. The mathematical model showed that the $\mathrm{C}_{5+}$ yields were improved, and the amounts of $\mathrm{CH}_{4}$ and $\mathrm{CO}_{2}$ byproducts were reduced by the use of a countercurrent $\mathrm{H}_{2}$-permselective membrane FTS reactor in sequence after the OCM reactor. In cocurrent and countercurrent reactors, there was an increase in the $\mathrm{C}_{5+}$ yields compared to those achieved using the conventional reactor.

\section{Conclusions and future trends}

In this review, an extensive overview of membrane materials and membrane reactors for the FTS process is presented. This technology can be used in the BtL process for the production of clean $2 \mathrm{G}$ liquid biofuels and chemicals for the transportation sector.

The different types of conventional FTS reactors show mass and heat transfer limitations. To overcome these limitations, integrating membrane reactors into the reactors is an interesting alternative to explore. In addition, these novel reactors are some of the most efficient reactors for increasing the CO conversion and adjusting the FTS 


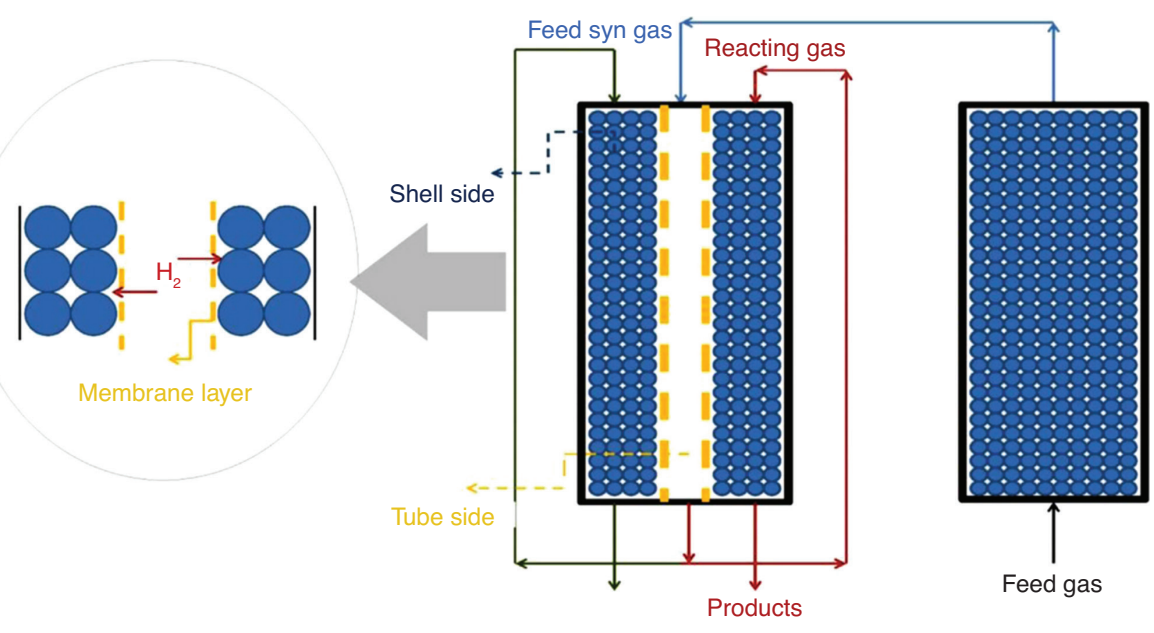

Figure 15: Scheme of two consecutive reactors: OCM reactor and FTS membrane reactor (reprinted from Ghareghashi et al. 2013a, copyright 2013, with permission from Elsevier).

reaction product distribution. The most studied FTS membrane reactors are the hydrogen distributive and water removal configurations; in both cases, the $\mathrm{CO}$ conversion is increased compared to using conventional reactors. For the hydrogen distributive configuration, the Pd-Ag alloy membranes are currently the best option; in addition, it has been demonstrated that higher $\mathrm{C}_{5+}$ and lower $\mathrm{C}_{1}$ products can be obtained in this configuration compared with a fixed-bed reactor working under the same experimental conditions.

For configurations focusing on water removal, zeolite membranes have been widely studied, but it is difficult to prepare defect-free membranes. On the other hand, carbon molecular sieve membranes can be a good alternative for this configuration.

In addition to the distributive and extractive configurations, other membrane reactor configurations have been described: forced-through-flow, zeolite encapsulated catalyst and dual-bed membrane reactors. These configurations showed an increase in the desired product yield (i.e. $\mathrm{C}_{5+}$ ) and a decrease in unfavorable product yield (i.e. $\mathrm{CO}_{2}$ ) compared to conventional reactors.

Although there are still some challenges to overcome in bringing this technology to the market, membrane reactors have great potential for application in FTS reactors.

Acknowledgments: The authors acknowledge Project ENE2016-77055-C3-3-R from the Ministerio de Economia y Competitividad. In addition, the authors would like to thank the Membrane Technology and Process Intensification Department and the Sustainable Chemistry Department at Tecnalia and the Group of Energy and Sustainable Chemistry at CSIC.

\section{References}

Aoki K, Kusakabe K, Morooka S. Separation of gases with an A-type zeolite membrane. Ind Eng Chem Res 2000; 39: 2245-2251.

Arratibel Plazaola A, Pacheco Tanaka DA, Van Sint Annaland M, Gallucci F. Recent advances in Pd-based membranes for membrane reactors. Molecules 2017; 22: 51.

Atkinson D. Fischer-Tropsch reactors for biofuels production: new technology needed! Biofuels Bioprod Biorefin 2010; 4: 12-16.

Bartholomew CH. Mechanisms of catalyst deactivation. Appl Catal A Gen 2001; 212: 17-60.

Bartholomew CH, Farrauto RJ. Fischer Tropsch synthesis. Hoboken, NJ, USA: John Wiley \& Sons Inc., 2006: 398-472.

Bartholomew $\mathrm{CH}$, Farrauto RJ. Fundamentals of industrial catalytic processes. Hoboken, NJ, USA: John Wiley \& Sons, 2011.

Boyer C, Gazarian J, Lecocq V, Maury S, Forret A, Schweitzer JM, Souchon V. Development of the Fischer-Tropsch process: from the reaction concept to the process book. Oil Gas Sci Technol 2016; 71: 44.

Bradford MCJ, Te M, Pollack A. Monolith loop catalytic membrane reactor for Fischer-Tropsch synthesis. Appl Catal A Gen 2005; 283: 39-46.

Brandberg Å, Hjortsberg H, Saevbark B, Ekbom T, Hjerpe C-J, Landaelv I. BioMeeT - planning of biomass based methanol energy combine - Trollhättan region - Final report. Ecotraffic R\&D AB. Available at: https://www.osti.gov/etdeweb/servlets/ purl/20086721 (accessed: October 2019), 2000.

Bridgwater AV. The technical and economic feasibility of biomass gasification for power generation. Fuel 1995; 74: 631-653.

Carballo JMG, Yang J, Holmen A, García-Rodríguez S, Rojas S, Ojeda $M$, Fierro JLG. Catalytic effects of ruthenium particle size on the Fischer-Tropsch synthesis. J Catal 2011; 284: 102-108.

Dahmen N, Dinjus E, Kolb T, Arnold U, Leibold H, Stahl R. State of the art of the bioliq ${ }^{\circledR}$ process for synthetic biofuels production. Environ Prog Sustain Energy 2012; 31: 176-181.

De Klerk A. Environmentally friendly refining: Fischer-Tropsch versus crude oil. Green Chem 2007; 9: 560-565. 
De Klerk A. Fischer-Tropsch fuels refinery design. Energy Environ Sci 2011; 4: 1177-1205.

De Klerk A, Maitlis PM. What can we do with Fischer-Tropsch products? Greener Fischer-Tropsch Processes for Fuels and Feedstocks. Weinheim, Germany: Wiley-VCH Verlag GmbH \& Co. KGaA, 2013: 81-105.

Den Breejen JP, Radstake PB, Bezemer GL, Bitter JH, Frøseth V, Holmen A, De Jong KP. On the origin of the cobalt particle size effects in Fischer-Tropsch catalysis. J Am Chem Soc 2009; 131: 7197-7203.

Deshmukh SR, Tonkovich ALY, Jarosch KT, Schrader L, Fitzgerald SP, Kilanowski DR, Lerou JJ, Mazanec TJ. Scale-up of microchannel reactors for Fischer - Tropsch synthesis. Ind Eng Chem Res 2010; 49: 10883-10888.

Deshmukh SR, Tonkovich ALY, McDaniel JS, Schrader LD, Burton CD, Jarosch KT, Simpson AM, Kilanowski DR, LeViness S. Enabling cellulosic diesel with microchannel technology. Biofuels 2011; 2: 315-324.

Dry ME. The Fischer-Tropsch process: 1950-2000. Catal Today 2002; 71: 227-241.

Eichenauer W. FA Lewis: The Palladium Hydrogen System. Academic Press, London and New York 1967. 178 Seiten, 87 Abbildungen. Preis: 45 s. Ber Bunsen Phys Chem 1967; 71: 1160-1161.

Ekbom T, Lindblom M, Berglin N, Ahlvik P. Technical and commercial feasibility study of black liquor gasification with methanol/ DME production as motor fuels for automotive uses - BLGMF. Nykomb Synergetics AB, Chemrec, Volvo, Ecotraffic, OKQ8, STFi, 2003.

Elekaei H, Forghani AA, Rahimpour MR. A comparative study of two $\mathrm{H} 2$-redistribution strategies along the FT reactor using H2-permselective membrane. Int J Energy Res 2011; 35: 321-335.

Espinoza RL, Du Toit E, Santamaria J, Menendez M, Coronas J, Irusta S. Use of membranes in Fischer-Tropsch reactors. Stud Surf Sci Catal 2000; 130: 389-394.

Espinoza RL, Santamaria JM, Menendez MA, Coronas J, Irusta S. Production of hydrocarbons, Google Patents, 2002.

Fernandez E, Medrano JA, Melendez J, Parco M, Viviente JL, van Sint Annaland M, Gallucci F, Tanaka DAP. Preparation and characterization of metallic supported thin Pd-Ag membranes for hydrogen separation. Chem Eng J 2016; 305: 182-190.

Fischer F, Tropsch H. The preparation of synthetic oil mixtures (synthol) from carbon monoxide and hydrogen. Brennstoff-Chem 1923; 4: 276-285.

Fischer N, Clapham B, Feltes T, van Steen E, Claeys M. Size-dependent phase transformation of catalytically active nanoparticles captured in situ. Angew Chem Int Ed 2014; 53: 1342-1345.

Flach B, Lieberz S, Rondon M, Williams B, Teiken C. EU biofuels annual 2015 NL5028. Washington, DC: Global Agricultural Information Network, 2015.

Forghani AA, Elekaei H, Rahimpour MR. Enhancement of gasoline production in a novel hydrogen-permselective membrane reactor in Fischer-Tropsch synthesis of GTL technology. Int J Hydrogen Energy 2009; 34: 3965-3976.

Foscolo PU. The unique project - integration of gasifier with gas cleaning and conditioning system. Sweden: International Seminar on Gasification, 2012.

Fritsch D, Randjelovic I, Keil F. Application of a forced-flow catalytic membrane reactor for the dimerisation of isobutene. Catal Today 2004; 98: 295-308.
Gallucci F, Fernandez E, Corengia P, van Sint Annaland M. Recent advances on membranes and membrane reactors for hydrogen production. Chem Eng Sci 2013; 92: 40-66.

Gallucci F, Annaland MVS, Gallucci K, Foscolo PU. Bioenergy intensified biomass utilization. In: Gallucci F, Van Sint Annaland $M$, editors. Process intensification for sustainable energy conversion. Chichester, UK: John Wiley \& Sons, 2015: 3839-3386.

Ghareghashi A, Ghader S, Hashemipour H. Theoretical analysis of oxidative coupling of methane and Fischer Tropsch synthesis in two consecutive reactors: comparison of fixed bed and membrane reactor. J Ind Eng Chem 2013a; 19: 1811-1826.

Ghareghashi A, Ghader S, Hashemipour H, Moghadam HR. A comparison of co-current and counter-current modes for Fischer-Tropsch synthesis in two consecutive reactors of oxidative coupling of methane and Fischer-Tropsch. J Nat Gas Sci Eng 2013b; 14: 1-16.

Gill SS, Tsolakis A, Dearn KD, Rodríguez-Fernández J. Combustion characteristics and emissions of Fischer-Tropsch diesel fuels in IC engines. Prog Energy Combust Sci 2011; 37: 503-523.

González Carballo JM, Finocchio E, García S, Rojas S, Ojeda M, Busca $G$, Fierro JLG. Support effects on the structure and performance of ruthenium catalysts for the Fischer-Tropsch synthesis. Catal Sci Technol 2011; 1: 1013-1023.

Gorbe J, Lasobras J, Francés E, Herguido J, Menéndez M, Kumakiri I, Kita H. Preliminary study on the feasibility of using a zeolite A membrane in a membrane reactor for methanol production. Separat Purific Technol 2018; 200: 164-168.

Guettel R, Kunz U, Turek T. Reactors for Fischer-Tropsch synthesis. Chem Eng Technol 2008; 31: 746-754.

Guillou L, Léonard S, Le Courtois V, Payen E, Vanhove D. Membrane reactors for Fischer-Tropsch synthesis, Proc. ICCMR-6, July 6-9, Lahnstein. 2004.

Hofbauer H, Knoef H. Success stories in biomass gasification. Handbook on biomass gasification. In: Knoef $\mathrm{H}$, editor. BTG Biomass Technology Group BV. Enschede, The Netherlands. 2005: 115-161.

Hashim SM, Mohamed AR, Bhatia S. Catalytic inorganic membrane reactors: present research and future prospects. Rev Chem Eng 2011; 27: 157-178.

Henis JMS, Tripodi MK. Composite hollow fiber membranes for gas separation: the resistance model approach. J Membr Sci 1981; 8: 233-246.

Herranz T, Rojas S, Pérez-Alonso FJ, Ojeda M, Terreros P, Fierro JLG. Genesis of iron carbides and their role in the synthesis of hydrocarbons from synthesis gas. J Catal 2006; 243: 199-211.

Hsieh HP. Inorganic membrane reactors. Catal Rev 1991; 33: 1-2, 1-70.

Iglesia E, Soled SL, Fiato RA. Fischer-Tropsch synthesis on cobalt and ruthenium. Metal dispersion and support effects on reaction rate and selectivity. J Catal 1992; 137: 212-224.

Ismail AF, David LIB. A review on the latest development of carbon membranes for gas separation. J Membr Sci 2001; 193: 1-18.

Jarosch K, Yang B, Fitzgerald S, Taha R, Mazanec T, Tonkovich A. Reduced complexity in the representation of Fischer-Tropsch chemistry. Prepr Pap Am Chem Soc Div Fuel Chem 2008; 53: $1-2$.

Jess A, Kern C. Modeling of multi-tubular reactors for FischerTropsch synthesis. Chem Eng Technol 2009; 32: 1164-1175. Kaidi (n.d.). Available at: http://www.kaidi.fi/english.

Khassin AA. Catalytic membrane reactor for conversion of syngas to liquid hydrocarbons. Energeia 2005; 16: 1-3. 
Khassin AA, Sipatrov AG, Yurieva TM, Chermashentseva GK, Rudina NA, Parmon VN. Performance of a catalytic membrane reactor for the Fischer-Tropsch synthesis. Catal Today 2005; 105: 362-366.

Kosinov N, Gascon J, Kapteijn F, Hensen EJM. Recent developments in zeolite membranes for gas separation. J Membr Sci 2016; 499: 65-79.

Lappas AA, latridis DK, Vasalos IA. Production of liquid biofuels in a fluid catalytic cracking pilot-plant unit using waxes produced from a biomass-to-liquid (BTL) process. Ind Eng Chem Res 2011; 50: 531-538.

Lin Y-C, Lee W-J, Wu T-S, Wang C-T. Comparison of PAH and regulated harmful matter emissions from biodiesel blends and paraffinic fuel blends on engine accumulated mileage test. Fuel 2006; 85: 2516-2523.

Liuzzi D, Pérez Alonso F, Fierro JLG, Rojas S, van Wijk F, Roghair I, Annaland MVS, Fernandez E, Viviente J, Tanaka DAP. Catalytic membrane reactor for the production of biofuels. Catal Today 2016a; 268: 37-45.

Liuzzi D, Pérez Alonso F, García García FJ, Calle Vallejo F, Fierro JLG, Rojas S. Identifying the time-dependent predominance regimes of step and terrace sites for the Fischer-Tropsch synthesis on ruthenium based catalysts. Catal Sci Technol 2016b; 6: 6495-6503.

Llosa Tanco MA, Pacheco Tanaka DA. Recent advances on carbon molecular sieve membranes (CMSMs) and reactors. Processes 2016; 4: 29.

Llosa Tanco MA, Pacheco Tanaka DA, Mendes A. Compositealumina-carbon molecular sieve membranes prepared from novolac resin and boehmite. Part II: effect of the carbonization temperature on the gas permeation properties. Int J Hydrogen Energy 2015a; 40: 3485-3496.

Llosa Tanco MAL, Pacheco Tanaka DA, Rodrigues SC, Texeira $M$, Mendes A. Composite-alumina-carbon molecular sieve membranes prepared from novolac resin and boehmite. Part I: preparation, characterization and gas permeation studies. Int J Hydrogen Energy 2015b; 40: 5653-5663.

Lødeng R, Hannevold L, Bergem H, Stöcker M. Catalytic hydrotreatment of bio-oils for high-quality fuel production. In: Triantafyllidis KS, Lappas AA, Stöcker M, editors. The role of catalysis for the sustainable production of bio-fuels and bio-chemicals. Amsterdam, The Netherlands: Elsevier, 2013: 351-396.

Lu Y, Lee T. Influence of the feed gas composition on the FischerTropsch synthesis in commercial operations. J Nat Gas Chem 2007; 16: 329-341.

Maitlis PM, de Klerk A. New directions, challenges, and opportunities. Greener Fischer-Tropsch Processes for Fuels and Feedstocks. Weinheim, Germany: Wiley-VCH Verlag GmbH \& Co. KGaA, 2013: 337-358.

MALTA Project (n.d.). Available at: https://www.maltaproiektua.es/.

Mardilovich PP, She Y, Ma YH, Rei MH. Defect-free palladium membranes on porous stainless-steel support. AIChe J 1998; 44: 310-322.

Mukkavilli S, Wittmann CV, Tavlarides LL. Carbon deactivation of Fischer-Tropsch ruthenium catalyst. Ind Eng Chem Process Des Dev 1986; 25: 487-494.

Müller-Langer F, Gröngröft A, Majer S, O’Keeffe S, Klemm M. Options for biofuel production - status and perspectives. In: Stolten $D$, Scherer V, editors. Transition to renewable energy systems. Weinheim, Germany: Wiley-VCH Verlag GmbH \& Co. KGaA, 2013: 523-553.
Murmura MA, Sheintuch M. Permeance inhibition of Pd-based membranes by competitive adsorption of $\mathrm{CO}$ : membrane size effects and first principles predictions. Chem Eng J 2018; 347: 301-312.

Nacken M, Ma L, Heidenreich S, Baron GV. Performance of a catalytically activated ceramic hot gas filter for catalytic tar removal from biomass gasification gas. Appl Catal B Environ 2009; 88: 292-298.

Najafi BF, Kibby CL, Song SX, Chinn D. Membrane reactor with in-situ dehydration and method for using the same. Google Patents, 2009.

Ogunkoya D, Fang T. Engine performance, combustion, and emissions study of biomass to liquid fuel in a compressionignition engine. Energy Convers Manage 2015; 95: 342-351.

Okamoto K-I, Kawamura S, Yoshino M, Kita H, Hirayama Y, Tanihara N, Kusuki Y. Olefin/paraffin separation through carbonized membranes derived from an asymmetric polyimide hollow fiber membrane. Ind Eng Chem Res 1999; 38: 4424-4432.

Okazaki J, Tanaka DAP, Tanco MAL, Wakui Y, Mizukami F, Suzuki TM. Hydrogen permeability study of the thin $\mathrm{Pd}-\mathrm{Ag}$ alloy membranes in the temperature range across the $\alpha-\beta$ phase transition. J Membr Sci 2006; 282: 370-374.

Peters T, Caravella A. Pd-based membranes: overview and perspectives. Basel, Switzerland: MDPI - Multidisciplinary Digital Publishing Institute, 2019.

Peters TA, Stange M, Veenstra P, Nijmeijer A, Bredesen R. The performance of $\mathrm{Pd}-\mathrm{Ag}$ alloy membrane films under exposure to trace amounts of $\mathrm{H}_{2}$ S. J Membr Sci 2016; 499: 105-115.

Ptasinski KJ. Efficiency of biomass energy: an exergy approach to biofuels, power, and biorefineries. New York: Wiley, 2016.

Rabou LPLM, Zwart RWR, Vreugdenhil BJ, Bos L. Tar in biomass producer gas, the Energy research Centre of the Netherlands $(E C N)$ experience: an enduring challenge. Energy Fuels 2009; 23: 6189-6198.

Rafati M, Wang L, Dayton DC, Schimmel K, Kabadi V, Shahbazi A. Techno-economic analysis of production of Fischer-Tropsch liquids via biomass gasification: the effects of Fischer-Tropsch catalysts and natural gas co-feeding. Energy Convers Manage 2017; 133: 153-166.

Rahimpour MR, Elekaei H. A comparative study of combination of Fischer-Tropsch synthesis reactors with hydrogenpermselective membrane in GTL technology. Fuel Process Technol 2009; 90: 747-761.

Rahimpour MR, Mirvakili A, Paymooni K. A novel water perm-selective membrane dual-type reactor concept for Fischer-Tropsch synthesis of GTL (gas to liquid) technology. Energy 2011; 36: 1223-1235.

Rahimpour MR, Samimi F, Babapoor A, Tohidian T, Mohebi S. Palladium membranes applications in reaction systems for hydrogen separation and purification: a review. Chem Eng Process Process Intensific 2017; 121: 24-49.

Rapagnà S, Jand N, Kiennemann A, Foscolo PU. Steam-gasification of biomass in a fluidised-bed of olivine particles. Biomass Bioenergy 2000; 19: 187-197.

Rohde MP. In-situ $\mathrm{H}_{2} \mathrm{O}$ removal via hydrophilic membranes during Fischer-Tropsch and other fuel related synthesis reactions. Karlsruhe, Germany: KIT Scientific Publishing, 2011.

Rohde MP, Unruh D, Schaub G. Membrane application in Fischer - Tropsch synthesis to enhance $\mathrm{CO}_{2}$ hydrogenation. Ind Eng Chem Res 2005a; 44: 9653-9658. 
Rohde MP, Unruh D, Schaub G. Membrane application in FischerTropsch synthesis reactors - overview of concepts. Catal Today 2005b; 106: 143-148.

Ronde MP, Schaub G, Vente JF, Van Veen HM. Fischer-Tropsch synthesis with in-situ $\mathrm{H}_{2} \mathrm{O}$ removal by a new hydrophilic membrane - an experimental and modelling study. DGMK, Tagungsbericht, 2006.

Saeidi S, Amin NAS, Rahimpour MR. Hydrogenation of $\mathrm{CO}_{2}$ to value-added products - a review and potential future developments. J CO, Utiliz 2014a; 5: 66-81.

Saeidi S, Amiri MT, Amin NAS, Rahimpour MR. Progress in reactors for high-temperature Fischer-Tropsch process: determination place of intensifier reactor perspective. Int J Chem Reactor Eng 2014b; 12: 639-664.

Saeidi S, Nikoo MK, Mirvakili A, Bahrani S, Amin NAS, Rahimpour MR. Recent advances in reactors for low-temperature FischerTropsch synthesis: process intensification perspective. Rev Chem Eng 2015; 31: 209-238.

Salleh WNW, Ismail AF. Carbon membranes for gas separation processes: recent progress and future perspective. J Membr Sci Res 2015; 1: 2-15.

Salomón MA, Coronas J, Menéndez M, Santamaría J. Synthesis of MTBE in zeolite membrane reactors. Appl Catal A Gen 2000; 200: 201-210.

Steynberg AP, Dry ME. Fischer-Tropsch technology. Amsterdam: Elsevier, 2004.

Storsæter S, Borg $\emptyset$, Blekkan EA, Holmen A. Study of the effect of water on Fischer-Tropsch synthesis over supported cobalt catalysts. J Catal 2005; 231: 405-419.

Swain PK, Das LM, Naik SN. Biomass to liquid: a prospective challenge to research and development in 21st century. Renew Sustain Energy Rev 2011; 15: 4917-4933.

Teixeira M, Campo MC, Tanaka DAP, Tanco MAL, Magen C, Mendes A. Composite phenolic resin-based carbon molecular sieve membranes for gas separation. Carbon 2011; 49: 4348-4358.
Teixeira M, Campo M, Tanaka DA, Tanco MA, Magen C, Mendes A. Carbon- $\mathrm{Al}_{2} \mathrm{O}_{3}-\mathrm{Ag}$ composite molecular sieve membranes for gas separation. Chem Eng Res Design 2012; 90: 2338-2345.

Tosti S, Basile A, Bettinali L, Borgognoni F, Gallucci F, Rizzello C. Design and process study of Pd membrane reactors. Int J Hydrogen Energy 2008; 33: 5098-5105.

Triantafyllidis K, Lappas A, Stöcker M, Elsevier BV, editors. The role of catalysis for the sustainable production of bio-fuels and bio-chemicals. Amsterdam, The Netherlands: Newnes, 2013.

Tsakoumis NE, Walmsley JC, Rønning M, van Beek W, Rytter E, Holmen A. Evaluation of reoxidation thresholds for $\gamma-\mathrm{Al}_{2} \mathrm{O}_{3}$ supported cobalt catalysts under Fischer-Tropsch synthesis conditions. J Am Chem Soc 2017; 139: 3706-3715.

Unruh D, Pabst K, Schaub G. Fischer - Tropsch synfuels from biomass: maximizing carbon efficiency and hydrocarbon yield. Energy Fuels 2010; 24: 2634-2641.

Velocys - Biorefineries (n.d.). Available at: https://www.velocys. com/projects/bayou-fuels/.

Wolf M, Kotzé H, Fischer N, Claeys M. Size dependent stability of cobalt nanoparticles on silica under high conversion FischerTropsch environment. Faraday Discuss 2017; 197: 243-268.

Xu L, Rungta M, Brayden MK, Martinez MV, Stears BA, Barbay GA, Koros WJ. Olefins-selective asymmetric carbon molecular sieve hollow fiber membranes for hybrid membrane-distillation processes for olefin/paraffin separations. J Membr Sci 2012; 423: 314-323.

Xu J, Yang Y, Li Y-W. Recent development in converting coal to clean fuels in China. Fuel 2015; 152: 122-130.

Yun S, Oyama ST. Correlations in palladium membranes for hydrogen separation: a review. J Membr Sci 2011; 375: 28-45.

Zennaro R, Ricci M, Bua L, Querci C, Carnelli L, d'Arminio Monforte A. Syngas: the basis of Fischer-Tropsch. Greener Fischer-Tropsch Processes for Fuels and Feedstocks. Weinheim, German: WileyVCH Verlag GmbH \& Co. KGaA, 2013: 17-51. 